\title{
The hydrostatic/hydrodynamic behaviour of an axial piston pump slipper with multiple lands
}

J.M. Bergada ${ }^{1}$, J. Watton ${ }^{2}$, J.M. Haynes ${ }^{2}$ and D. Ll. Davies ${ }^{2}$

${ }^{1}$ Fluid Mechanics Department ETSEIT UPC, Colon 11 Terrassa 08222, Spain. Tel. 0034-937398771. Fax. 0034-937398101. bergada@mf.upc.edu

${ }^{2}$ Cardiff School of Engineering. Cardiff University. Queen's Buildings.

The parade, Cardiff CF24 3AA Wales UK. Tel. 0044-2920874315. wattonj@cardiff.ac.uk; haynesjm@cardiff.ac.uk; daviesdll@cardiff.ac.uk

\begin{abstract}
This study considers an analytical approach towards the understanding of the hydrostatic leakage and lift characteristic of a flat slipper of the type used for piston/slipper units within an axial piston pump or motor. In particular it considers a slipper design incorporating a groove on the slipper face and also includes the effect of motion around its associated swash plate. A new set of equations are developed and in generic form for a slipper with any number of grooves. Experimental comparisons are then undertaken and extended to include the effect of relative motion around the swash plate and slipper tilt. A CFD study of the slipper is also presented. Comparisons between analytical, experimental and CFD results show a very good agreement, validating the equations presented and extending the conclusions when tilt and tangential speed are considered.
\end{abstract}

Key words: axial piston slipper, multiple lands, analytical solution, measurements, CFD. 


\section{Nomenclature.}

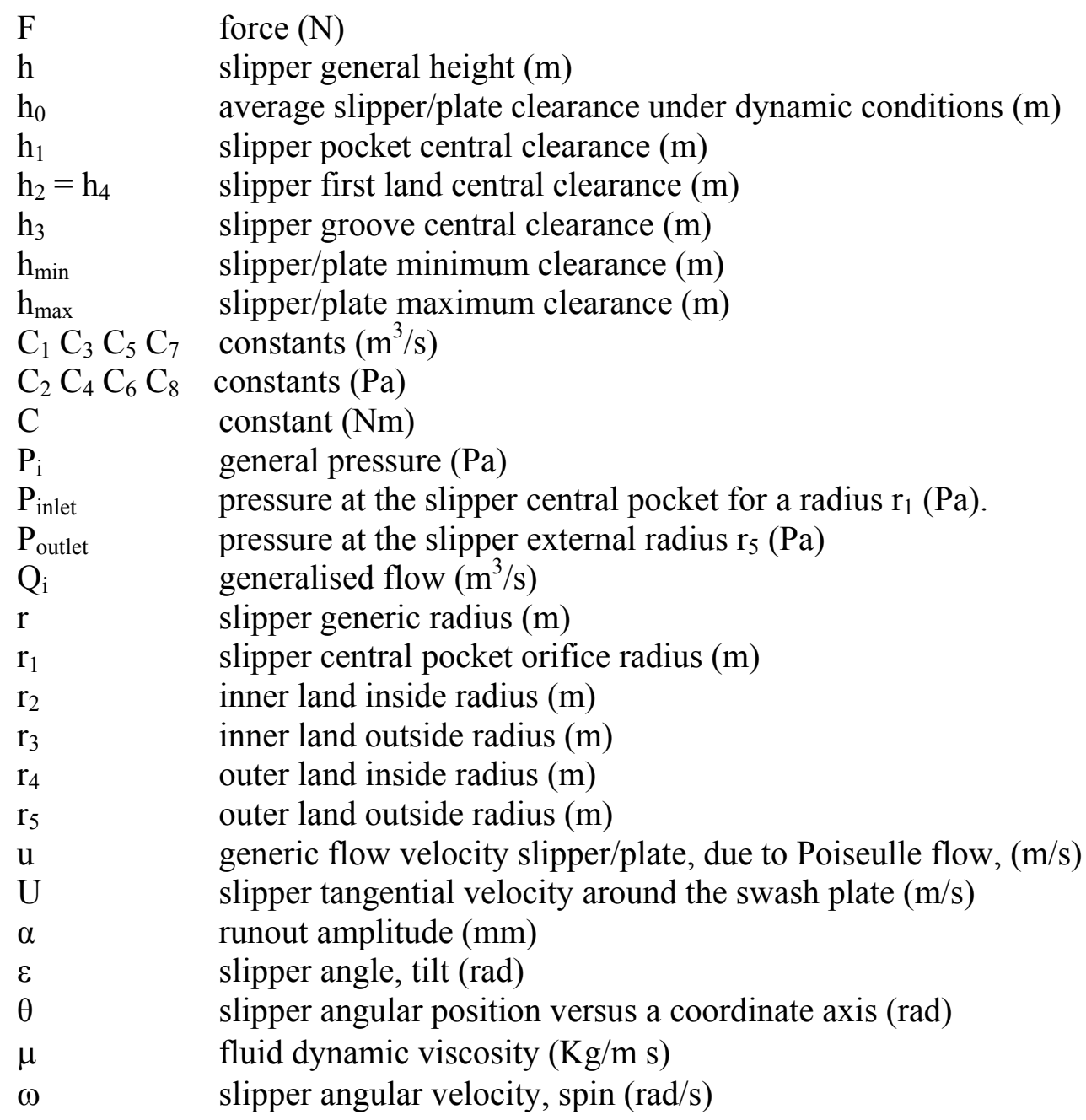

\section{Introduction.}

A good analytical understanding of slipper behaviour in piston pumps and motors is crucial to good design. A large amount of work has been done in this area, but very little has focused on understanding the effect of grooves on the slippers face. The general behaviour of a slipper will not drastically change when grooves are added, but their addition does modify the pressure distribution, leakage, and force acting over the slipper and this gives added design freedom. The importance of a detailed understanding is made relevant when it is realised that most of the leakage in piston pumps and motors occurs through each piston/slipper assembly. Efficiency and performance of axial piston positive displacement 
machines is directly linked with a good slipper/swash plate interaction, this being necessary to avoid metal to metal contact or excessive film thicknesses with consequential high leakages. Friction between the slipper/piston-spherical bearing as pointed out by Hooke et al [1] and Kobayashi et al [2] plays an important role regarding slipper dynamics. Therefore, volumetric, hydraulic and mechanic efficiencies in piston pumps and motors will be directly affected by slipper performance. In the majority of the publications presented until now, the effect of multiple pressure balancing grooves has been neglected. Despite the fact that the groove effect on the flow and the pressure distribution is not expected to give a completely different pattern from previous knowledge using single-land slippers, the introduction of a groove requires further new mathematical analysis when aiming to fully understand its behaviour.

The main piston and slipper assembly used in this study is shown in Figure 1, and is one of the nine pistons from a pump having a maximum volumetric displacement of $31 \mathrm{cc} / \mathrm{rev}$. It will be seen that the slipper design has two full lands, an alternative being to machine additional slots across the second land to balance the groove and outlet pressure. The approach selected seems to be the design philosophy of the particular pump manufacturer and can vary between manufacturers.

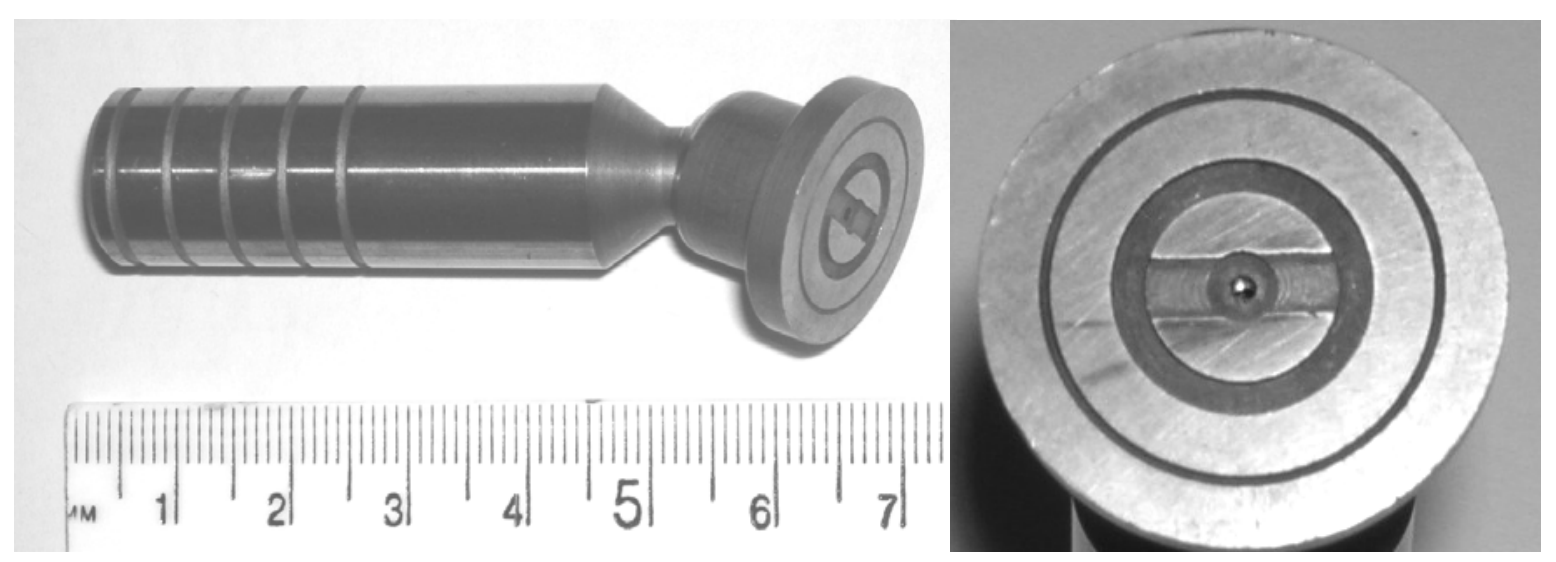

Figure 1. Piston and slipper assembly studied 
There have been many publications in this general subject area over the past 30 years, many concerned with improving the slipper performance of piston pumps and motors. Most of the work has focused on analysing the forces and torques over the slipper, experimentally, analytically and via numerical simulation. [3-14, 19, 20,]. The effects of slipper spin, tangential velocity, tilt, slipper non flatness, inlet orifice, and conditions for metal to metal contact, amongst others, have been investigated. The performance of composite slippers working with water based fluids has been studied by Li and Hooke [15] and the torque created on the spherical piston slipper interface and its effect onto the slipper dynamic performance has also been considered $[1,2,16]$. Slipper dynamic performance over one complete revolution was investigated by $[17,18]$ finding a large variation in slipper central clearance and tilt depending on piston connection with tank or outlet ports. The performance of slippers with grooves was reported by $[4,12,13,21]$ in which it was found that a groove brought stability to the slipper dynamics. In all these cases the second land was vented and therefore the pressure on the groove was reported to be atmospheric. As a result the groove itself was not creating lift. It was also reported that for a given central clearance, reducing the number of lands gives a reduction in leakage. The most advanced analytical study on non-tilt slippers without a groove was presented in Johnson and Manring [22], where Reynolds equation of lubrication was integrated considering the effect of tangential velocity.

The solution of Reynolds equation, in which radial and angular pressure distribution is taken into account, has been performed via solving the differential equation as a power series $[3,6,13,14,20]$. An analytical solution for slippers with multiple lands was outlined in Bergada and Watton [23-25] and also in Watton [26, 27], another work by Bergada et al [28] considered tilt but with no tangential speed effects. The consideration of slipper spin 
and tangential velocity on tilt slippers with grooves needs the use of the three dimensional Navier Stokes equations in cylindrical coordinates. For the case of non-tilted slippers with a groove, an introductory work is presented by Kumar et al [29], where the flow Vorticity inside the groove was numerically determined for different groove dimensions. A good research regarding the lubrication characteristics of water hydraulic slippers was done by Huanlong et al [30], where they presented and experimental and CFD research evaluating the leakage and pressure distribution in a conventional slipper and a new model one called three-cavity independent slipper working with a water based fluid, they conclude that the new design improve the anti-turnover ability of the slipper, decreasing the metal to metal contact while working.

Very recently, Canbulut et al [31-33], studied experimentally and via a neural network model, considering dynamic conditions, the performance of none grooved slippers for different dimensions, roughness, piston capillary tube diameter and tangential velocities, they found the optimum surface roughness to minimise the power loss, they noticed that the slipper frictional power loss, decrease with the increase of tangential velocity, and also with the increase of the piston capillary tube diameter. The neural network model they developed proved to be very useful in predicting the slipper behaviour and conclude saying that such neural network models can be used in real time applications. The advantages of using conical slippers were also explained.

In the present study, the effect of tangential velocity on flat and tilt slippers is presented via experimental research. The beauty of the new set of equations to be presented is that despite their simplicity, they bring a deep understanding of the slipper behaviour. Regarding the analytical study, the following assumptions are appropriate: 
- Flow will be considered laminar and incompressible in all cases

- The flow is hydraulic mineral oil ISO 32

- Static conditions for the slipper and the plate are considered

- Flow will be radially dominant

- The slipper is considered as a rigid body, no mechanical deformation is considered

2 Mathematical analysis for flat slippers with multiple lands.

Reynolds equation of lubrication applied to the slipper/swash plate gap when the slipper moves tangentially with a velocity " $U$ ", spins with an angular velocity " $\omega$ " and has a tilt which depends on the slipper angular position" $\theta$ " and the slipper radius " $r$ " is given in cylindrical coordinates according to [34], chapter three, as equation (1).

$\frac{1}{\mathrm{r}^{2}} \frac{\partial}{\partial \theta}\left(\mathrm{h}^{3} \frac{\partial \mathrm{p}}{\partial \theta}\right)+\frac{1}{\mathrm{r}} \frac{\partial}{\partial \mathrm{r}}\left(\mathrm{rh}^{3} \frac{\partial \mathrm{p}}{\partial \mathrm{r}}\right)=6 \mu\left(\mathrm{U} \cos \theta \frac{\partial \mathrm{h}}{\partial \mathrm{r}}-\frac{\mathrm{U} \sin \theta}{\mathrm{r}} \frac{\partial \mathrm{h}}{\partial \theta}+\omega \frac{\partial \mathrm{h}}{\partial \theta}\right)$

In this equation, the slipper angular position is represented by " $\theta$ " which has a value between 0 and 360 degrees, the slipper tilt is considered by the terms $\frac{\partial \mathrm{h}}{\partial \mathrm{r}}$ and $\frac{\partial \mathrm{h}}{\partial \theta}$.

When considering constant viscosity, slipper without tilt and no relative movement between slipper and plate, the equation becomes:

$\frac{\partial}{\partial \mathrm{r}}\left(\frac{\mathrm{rh}^{3}}{\mu} \frac{\partial \mathrm{p}}{\partial \mathrm{r}}\right)=0$

Its integration yields:

$$
\mathrm{P}=\frac{\mathrm{C}_{1} \mu}{\mathrm{h}^{3}} \ln \mathrm{r}+\mathrm{C}_{2}
$$

$\mathrm{C}_{1}$ and $\mathrm{C}_{2}$ are constants which have to be found from the boundary conditions.

The equations representing velocity profile and flow rate between two cylindrical flat plates separated by a very small gap and for a pressure differential between the inner and outer radius is given by:

$$
\mathrm{u}=-\frac{1}{\mu} \frac{\mathrm{dp}}{\mathrm{dr}} \frac{\mathrm{y}}{2}(\mathrm{~h}-\mathrm{y})
$$


$\mathrm{Q}=\int_{0}^{\mathrm{h}} \mathrm{u} 2 \pi \mathrm{rdy}=-\frac{\pi \mathrm{r}}{\mu} \frac{\mathrm{dp}}{\mathrm{dr}} \frac{\mathrm{h}^{3}}{6}$

Substituting the first derivative of equation (2) into equation (5) yields:

$\mathrm{Q}=-\pi \frac{\mathrm{C}_{1}}{6}$

Equations (3) and (6) give the pressure distribution and radial flow between the gap of two cylindrical flat plates. To find the constants $\mathrm{C}_{1}$ and $\mathrm{C}_{2}$, knowledge of two boundary conditions is required:

$\mathrm{r}=\mathrm{r}_{\mathrm{i}} ; \mathrm{p}=\mathrm{p}_{\mathrm{i}}$

$\mathrm{r}=\mathrm{r}_{\mathrm{j}} ; \mathrm{p}=\mathrm{p}_{\mathrm{j}}$

Equations (3) and (6) can be applied to any number of consecutive cylindrical flat plates, understanding that the flow will be laminar at all points and having in mind that for every plate two new constants will appear. For the case under study a slipper with two lands and a groove separating them, Figure 2, can be established.

\section{Slipper pocket}

$\mathrm{p}_{1}=\mathrm{C}_{1} \frac{\mu}{\mathrm{h}_{0}^{3}} \ln \mathrm{r}+\mathrm{C}_{2} \quad$ range of applicability $\quad \mathrm{r}_{1}<\mathrm{r}<\mathrm{r}_{2}$

$\mathrm{Q}_{1}=-\frac{\pi \mathrm{C}_{1}}{6}$

First Land.

$\mathrm{p}_{2}=\mathrm{C}_{3} \frac{\mu}{\mathrm{h}_{1}^{3}} \ln \mathrm{r}+\mathrm{C}_{4} \quad$ range of applicability $\quad \mathrm{r}_{2}<\mathrm{r}<\mathrm{r}_{3}$

$\mathrm{Q}_{2}=-\frac{\pi \mathrm{C}_{3}}{6}$

\section{Groove}

$\mathrm{p}_{3}=\mathrm{C}_{5} \frac{\mu}{\mathrm{h}_{2}^{3}} \ln \mathrm{r}+\mathrm{C}_{6} \quad$ range of applicability $\quad \mathrm{r}_{3}<\mathrm{r}<\mathrm{r}_{4}$ 
$\mathrm{Q}_{3}=-\frac{\pi \mathrm{C}_{5}}{6}$

\section{Second Land}

$$
\begin{aligned}
& \mathrm{p}_{4}=\mathrm{C}_{7} \frac{\mu}{\mathrm{h}_{3}^{3}} \ln \mathrm{r}+\mathrm{C}_{8} \quad \text { range of applicability } \quad \mathrm{r}_{4}<\mathrm{r}<\mathrm{r}_{5} \\
& \mathrm{Q}_{4}=-\frac{\pi \mathrm{C}_{7}}{6}
\end{aligned}
$$

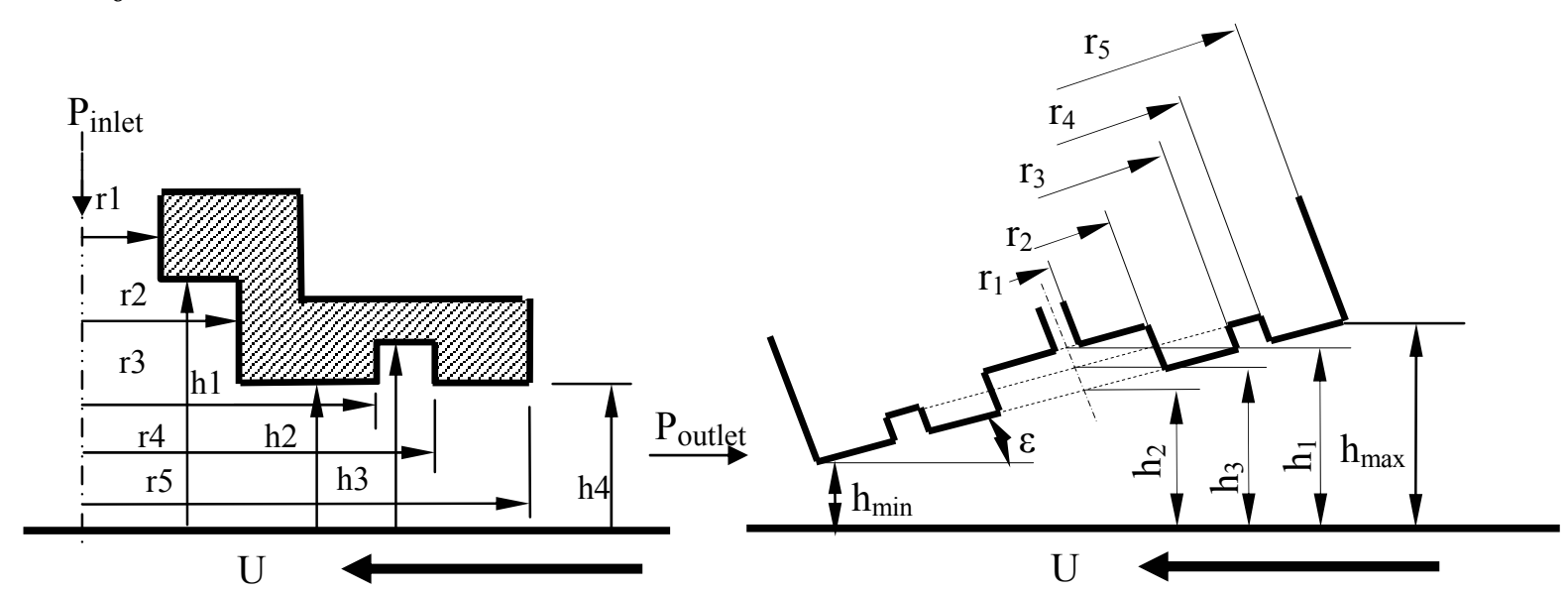

Figure 2. Diagram of the flat/tilt slipper under study with two main lands.

The boundary conditions are:

$\mathrm{r}=\mathrm{r}_{1} \quad \mathrm{p}_{1}=\mathrm{p}_{\text {inlet }}$

$\mathrm{r}=\mathrm{r}_{2} \quad \mathrm{p}_{1}=\mathrm{p}_{2} \quad \mathrm{Q}_{1}=\mathrm{Q}_{2}$

$\mathrm{r}=\mathrm{r}_{3} \quad \mathrm{p}_{2}=\mathrm{p}_{3} \quad \mathrm{Q}_{2}=\mathrm{Q}_{3}$

$\mathrm{r}=\mathrm{r}_{4} \mathrm{p}_{3}=\mathrm{p}_{4} \quad \mathrm{Q}_{3}=\mathrm{Q}_{4}$

$\mathrm{r}=\mathrm{r}_{5} \mathrm{p}_{4}=\mathrm{p}_{\text {outlet. }}$

It needs to be considered that Reynolds equation of lubrication must be used under laminar conditions. On the slipper first and second lands, the distance slipper plate, for a flat slipper, is constant and very narrow, usually around 5 to 15 microns, the fluid velocity is rather high, the Reynolds number is considered to be laminar. When the fluid enters the slipper, it faces the slipper central pocked, which depth for the case studied is $1.4 \mathrm{~mm}$, the flow when the slipper is held perfectly parallel to the plate (flat slipper) has to be 
considered radial, and the velocity will be very small, the Reynolds number will be much smaller than the one found in the slipper first and second lands, as a conclusion, the assumption of laminar flow is perfectly valid in the slipper pocked. Reynolds equation of lubrication it is absolutely applicable in the slipper pocked and under the conditions established. The same phenomenon happens in the slipper groove, which depth is $0.8 \mathrm{~mm}$. The assumption of flow in radial direction, it is perfectly true for a slipper held perfectly parallel to the plate, and under static conditions, under these conditions the flow is perfectly symmetric. The assumption of velocity parabolic profile, typical of laminar flow, it is perfectly correct in the slipper central pocked, groove, first and second lands.

Once the constants are found and substituted in equations (8)-(15), then the equations can be established describing the pressure distribution across the central pocked, each slipper land and the slipper groove, and the leakage flow between the slipper and plate. For the present case of a slipper with a central pocked, first land, groove and second land, total number of flat plates (total lands), $\mathrm{n}=4$, the equations are shown in the appendix.

Next, the generic equations giving the leakage flow and pressure distribution for a generic number of (total lands) " $n$ " are presented. The equation which gives the leakage flow between a slipper and plate for a slipper with a generic number of (total lands) "n", which include the slipper pocked, and the groove or grooves, takes the form. Notice that when talking about (total lands) the first land is in reality the slipper central pocked.

$$
\mathrm{Q}=\frac{\pi}{6 \mu} \frac{\left(\mathrm{p}_{\text {inlet }}-\mathrm{p}_{\text {outlet }}\right)}{\sum_{\mathrm{i}=1}^{\mathrm{i}=\mathrm{n}} \frac{1}{\mathrm{~h}_{\mathrm{i}}^{3}} \ln \frac{\mathrm{r}_{\mathrm{i}+1}}{\mathrm{r}_{\mathrm{i}}}}
$$

The generic pressure distribution for a slipper with any number of (total lands) " $n$ " will be: For the slipper pocked: $\mathrm{r}_{1}<\mathrm{r}<\mathrm{r}_{2}$. 


$$
\mathrm{p}_{1}=\mathrm{p}_{\text {inlet }}-\frac{\left(\mathrm{p}_{\text {inlet }}-\mathrm{p}_{\text {outlet }}\right)}{\sum_{\mathrm{i}=1}^{\mathrm{i}=\mathrm{n}} \frac{1}{\mathrm{~h}_{\mathrm{i}}^{3}} \ln \left(\frac{\mathrm{r}_{\mathrm{i}+1}}{\mathrm{r}_{\mathrm{i}}}\right)}\left[\frac{1}{\mathrm{~h}_{1}^{3}} \ln \left(\frac{\mathrm{r}}{\mathrm{r}_{1}}\right)\right]
$$

For the rest of the lands, including the groove: $2<\mathrm{j}<\mathrm{n}$;

$$
\mathrm{p}_{\mathrm{j}}=\mathrm{p}_{\text {inlet }}-\frac{\left(\mathrm{p}_{\text {inlet }}-\mathrm{p}_{\text {outlet }}\right)}{\sum_{\mathrm{i}=1}^{\mathrm{i}=\mathrm{n}} \frac{1}{\mathrm{~h}_{\mathrm{i}}^{3}} \ln \left(\frac{\mathrm{r}_{\mathrm{i}+1}}{\mathrm{r}_{\mathrm{i}}}\right)}\left[\frac{1}{\mathrm{~h}_{\mathrm{j}}^{3}} \ln \left(\frac{\mathrm{r}}{\mathrm{r}_{\mathrm{j}}}\right)+\sum_{\mathrm{k}=1}^{\mathrm{k}=\mathrm{j}-1} \frac{1}{\mathrm{~h}_{\mathrm{k}}^{3}} \ln \left(\frac{\mathrm{r}_{\mathrm{k}+1}}{\mathrm{r}_{\mathrm{k}}}\right)\right]
$$

The lift force can be found by integrating the radial pressure. Since the slipper under study has an inner pocket and two lands separated by a groove, the integral has to be split into four parts as follows:

$$
F_{\text {lift }}=\int_{r_{1}}^{r_{2}} P_{1}(r) 2 \pi r d r+\int_{r_{2}}^{r_{3}} P_{2}(r) 2 \pi r d r+\int_{r_{3}}^{r_{4}} P_{3}(r) 2 \pi r d r+\int_{r_{4}}^{r_{5}} P_{4}(r) 2 \pi r d r
$$

where for $n=4, P_{1}(r), P_{2}(r), P_{3}(r)$ and $P_{4}(r)$ are given by the equations (24) to (27), presented in the appendix. The equation giving the lift force on the slipper is also presented in the appendix. The generic lift force equation for a slipper with any number of (total lands) is now developed as follows:

$$
\mathrm{F}_{\text {lift }}=\mathrm{P}_{\text {inlet }} \pi\left(\mathrm{r}_{(\mathrm{n}+1)}^{2}-\mathrm{r}_{1}^{2}\right)-\mathrm{C} \pi \mathrm{r}_{(\mathrm{n}+1)}^{2} \sum_{\mathrm{i}=1}^{\mathrm{i}=\mathrm{n}} \frac{1}{\mathrm{~h}_{\mathrm{i}}^{3}} \ln \left(\frac{\mathrm{r}_{(\mathrm{i}+1)}}{\mathrm{r}_{\mathrm{i}}}\right)+\mathrm{C} \pi \sum_{\mathrm{i}=1}^{\mathrm{i}=\mathrm{n}} \frac{1}{\mathrm{~h}_{\mathrm{i}}^{3}} \frac{\mathrm{r}_{(\mathrm{i}+1)}^{2}-\mathrm{r}_{\mathrm{i}}^{2}}{2}
$$

where:

$$
\mathrm{C}=\frac{\mathrm{P}_{\text {inlet }}-\mathrm{P}_{\text {outlet }}}{\sum_{\mathrm{i}=1}^{\mathrm{i}=\mathrm{n}} \frac{1}{\mathrm{~h}_{\mathrm{i}}^{3}} \ln \left(\frac{\mathrm{r}_{(\mathrm{i}+1)}}{\mathrm{r}_{\mathrm{i}}}\right)}
$$

It is now analytically possible to determine the condition for maximum lift using the previously derived set of equations.

\section{Experimental measurements.}

In order to experimentally validate the equations presented, two test rigs were constructed and Figure 3 shows test rig 1. Notice that slipper scale used is 2:1. 

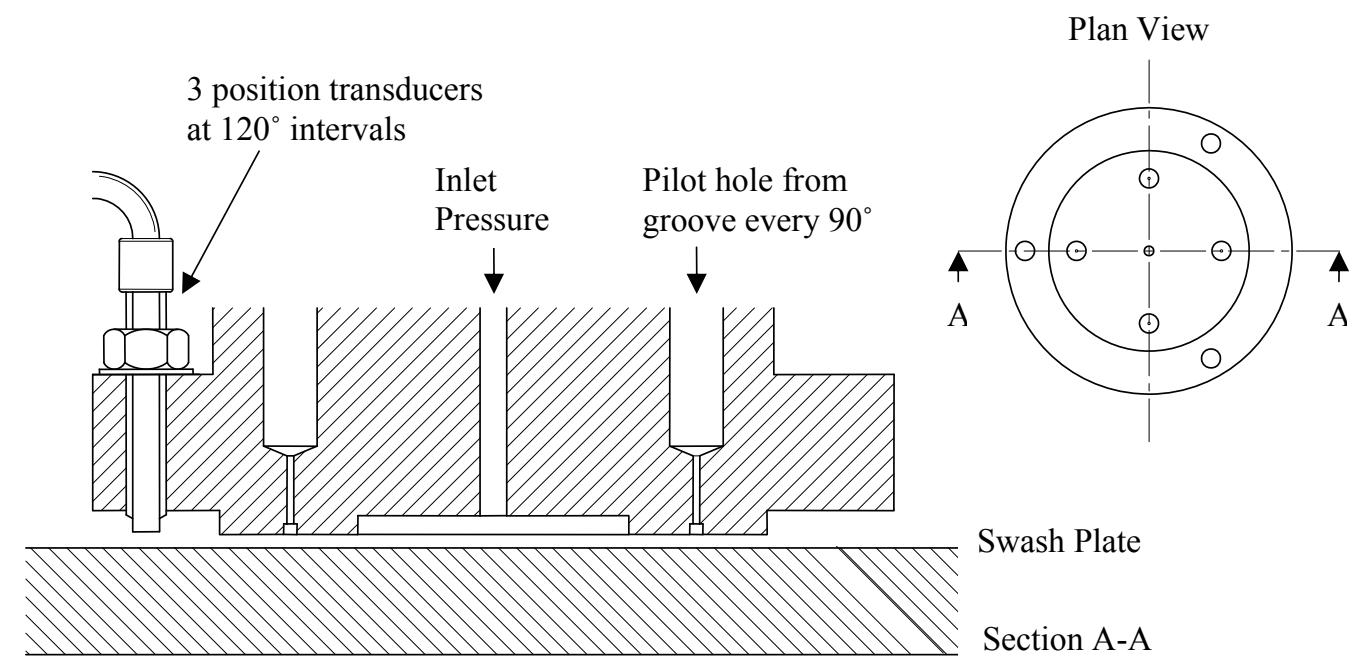

a) Cross section of the slipper area

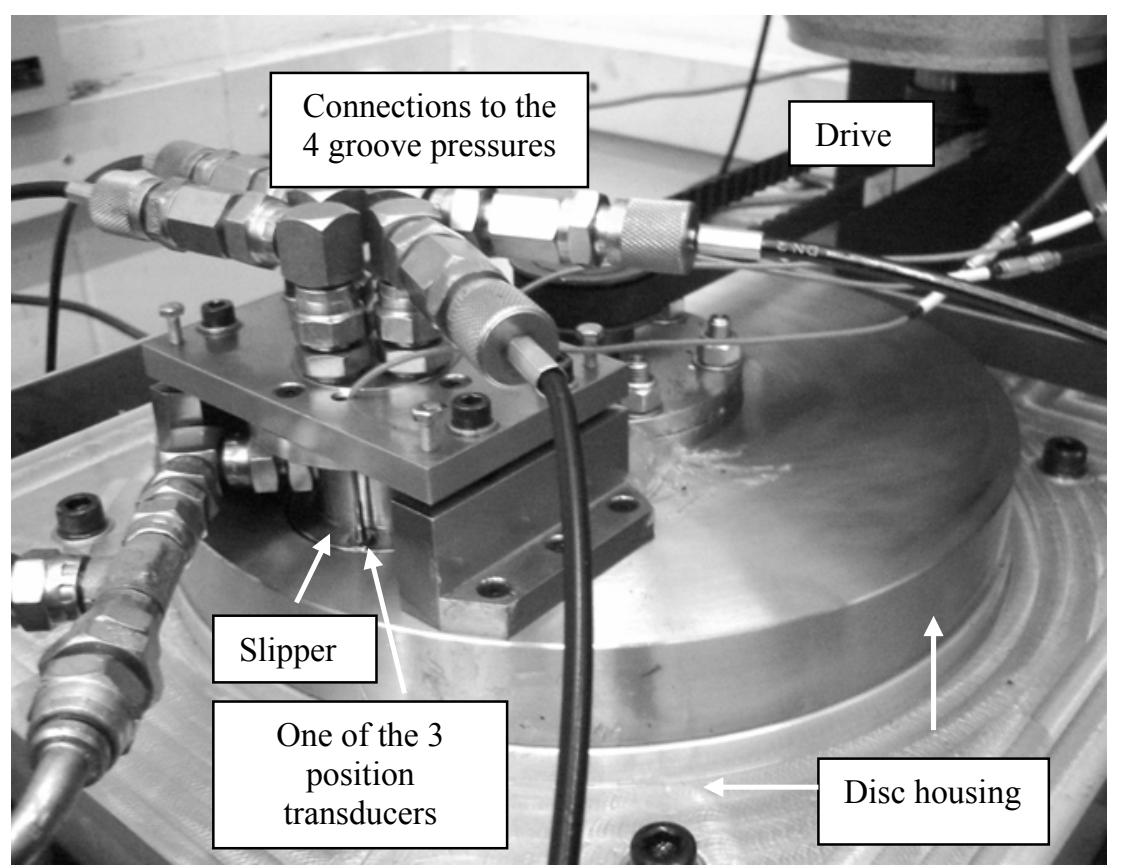

b) Slipper, disc housing and drive system

Figure 3. Test rig 1, slipper scale 2:1

Run-out is the dynamic variation in axial location of the disc during rotation and this was minimised by utilising three bearings. Under static conditions, when pressure is applied to the slipper the distance slipper plate may increase few microns, this is called test rig 
deflection, such deflection can be seen as static runout. A lower thrust bearing supports the disc in a vertical direction. This bearing also ensured that the disc could not move axially once hydraulic pressure was applied to the slipper. A roller bearing was used in conjunction with the thrust bearing, since the thrust bearing provided no radial support for the disc. This roller bearing was non-locating axially, and so ensured that all of the axial loads were supported by the thrust bearing. In addition, the slipper plate was designed so that the bearing surfaces and face of the plate could all be machined without removing the plate from the lathe.

Three position sensors, having a measurement accuracy of 0.1 microns, were attached to the slipper at $120^{\circ}$ intervals. These sensors require a non-ferrous measuring face for optimum performance and therefore a housing assembly plate was manufactured from aluminium, the slipper assembly being manufactured from stainless steel. The slipper is held in position using four screws and the required slipper orientation was achieved by turning four additional positioning screws. Using this method the slipper can be positioned completely parallel to the swash plate. Four holes, $0.3 \mathrm{~mm}$ diameter and at every $90^{\circ}$, were drilled at points around the slipper groove allowing measurement of the pressure inside the groove at its four cardinal positions. The slipper was built with a scale $2: 1$ when compared with the slipper that initiated this project, shown in Figure 1. This was done to be able to physically locate both the position sensors and the pressure measuring points. However, the size of the test rig slipper is not unlike those that exist in larger pumps. Both test rig slipper dimensions are as shown in Table 1. 
Table 1 Slipper dimensions for the two different test rigs

\begin{tabular}{|l|l|l|}
\hline Parameters. & Test rig 1. Slipper scale 2:1 & Test rig 2. Slipper scale 1:1 \\
\hline Orifice radius $\mathrm{r}_{1 .}$ & $1 \mathrm{~mm}$ & $0.5 \mathrm{~mm}$ \\
\hline Inner land inside radius $\mathrm{r}_{2}$. & $10.15 \mathrm{~mm}$ & $5 \mathrm{~mm}$ \\
\hline Inner land outside radius $\mathrm{r}_{3}$. & $14.7 \mathrm{~mm}$ & $7.4 \mathrm{~mm}$ \\
\hline Groove width. & $1 \mathrm{~mm}$ & $0.4 \mathrm{~mm}$ \\
\hline Outside radius $\mathrm{r}_{4}$. & $20,5 \mathrm{~mm}$ & $10.2 \mathrm{~mm}$ \\
\hline Film thickness $\mathrm{h}_{2}=\mathrm{h}_{4 .}$ & Modifiable 5 to $35 \mu \mathrm{m}$ & Modifiable 5 to $35 \mu \mathrm{m}$ \\
\hline Slipper pocked depth $\mathrm{h}_{1}$. & $\mathrm{h}_{2}+1.4 \mathrm{~mm}$ & $\mathrm{~h}_{2}+0.65 \mathrm{~mm}$ \\
\hline Groove depth $\mathrm{h}_{3}$. & $\mathrm{h}_{2}+0.8 \mathrm{~mm}$ & $\mathrm{~h}_{2}+0.4 \mathrm{~mm}$ \\
\hline
\end{tabular}

With test rig 1 it is possible to perform measurements for a flat or a tilted slipper, including the effect of tangential velocity. Tests were undertaken to study the effect of tangential velocity on slipper leakage and its groove pressure distribution, and for flat and tilted cases. For the case where slipper was held parallel to the disk, two initial static clearances of 15 microns and 20microns were studied. With slipper tilt, several initial static central clearances were also analysed and up to almost maximum angle. The different central clearances and angles studied are shown in Table 2.

Table 2 Tilted slipper test conditions.

\begin{tabular}{|ll|l|l|l|l|l|}
\hline Initial static central clearance $\quad \mathrm{h}_{2}$ & $(\mu \mathrm{m})$ & 8 & 10 & 12 & 15 & 20 \\
\hline Minimum clearance slipper/plate $\mathrm{h}_{\min }$ & $(\mu \mathrm{m})$ & 0.13 & 0.7 & 0.9 & 4.26 & 0.32 \\
\hline Maximum clearance slipper/plate $\mathrm{h}_{\max }(\mu \mathrm{m})$ & 15.87 & 19,3 & 23 & 25.7 & 39.67 \\
\hline Tilted angle $\varepsilon$ & $(\mathrm{deg})$ & 0.022 & 0.026 & 0.031 & 0.03 & 0.055 \\
\hline
\end{tabular}

The range of swash plate turning speeds studied varied from $200 \mathrm{rpm}$ to $1000 \mathrm{rpm}$, the maximum turning speed corresponding to a tangential velocity on the slipper main axis of $9.63 \mathrm{~m} / \mathrm{s}$. The first test rig allowed measurements of leakage across the slipper and pressure inside the groove, but pressure decay along the lands could not be measured.

To overcome this difficulty, a second and much simpler test rig was built as shown in Figure 4. 


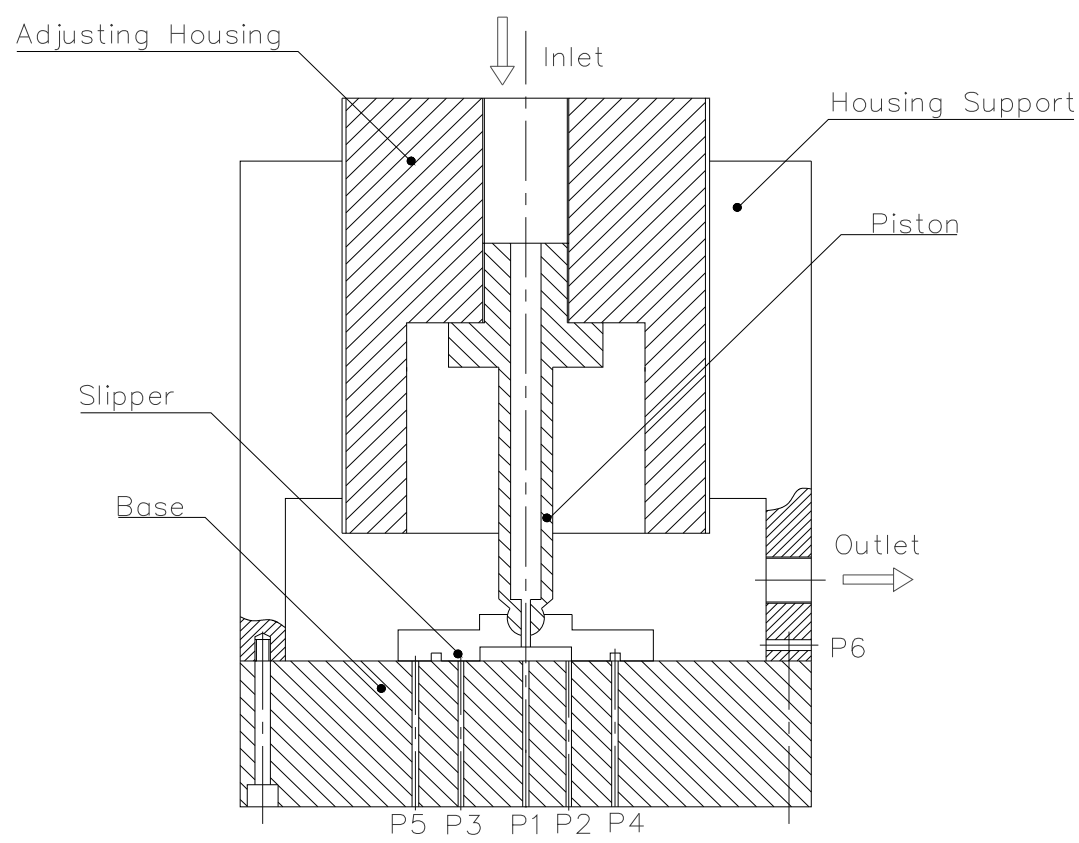

Figure 4. Test rig 2, slipper scale 1:1

This second test rig housed the actual piston/slipper assembly shown in Figure 1 and was only capable of static testing for the constant clearance condition. A micrometer gauge thread was machined on the adjuster allowing known clearances to be set and a range of noload clearances from 0 to 35 microns in 5 micron steps were studied and up to a maximum inlet pressure of $160 \mathrm{bar}$. However before the results are compared with theory it is essential to determine the actual clearance as pressure is applied. This is due to the small yet significant compression between the adjusting housing and the housing support fine thread, the net result being that the actual clearance increases with applied pressure. This compression was measured with a precision position transducer mounted to the bed plate holding the test unit and it was found that the compression increased to 4 microns as the pressure increased to $160 \mathrm{bar}$. The accuracy of the displacement transducer used to measure the relative displacement between the adjusting housing and the housing support was 
determined as \pm 0.25 microns. Pressure tappings in the base unit then allowed the pressure distribution to be measured across one axis of the slipper, using calibrated test Bourdon gauges, and including the groove.

\section{A CFD simulation.}

A three dimensional model of the slipper scale 2:1 including the groove, was developed using the Fluent 6.1 CFD package. The first model considered the slipper without tilt, under static conditions and for a clearance of 10 microns, maintaining the groove dimensions, the groove was positioned in three different radial locations, as will be seen in Figure 10. A second model considered the slipper with a central clearance of 10 microns and two very small tilts of 0.0014 and 0.0028 degrees, which corresponds to 1 and 2 microns tilt over the slipper diameter. Such small tilts are the ones expected to be found in practice. For all cases studied, the effect of plate turning speed in the range $0-1250 \mathrm{rpm}$, was considered. A single inlet pressure of 150 bar was used in all cases. The full Navier Stokes equations for laminar flow conditions were employed in all the models. In the present paper just the static case for flat slipper is being used to compare with the theoretical static equations presented in section 2. From the simulation undertaken and under static conditions, it can be stated that for the small tilts studied the pressure distribution along the slipper diameter remains very much the same as the one found for the flat slipper case.

\section{Results.}

\subsection{Slipper analysis under static conditions.}

\subsubsection{Leakage and pressure distribution with no tilt.}

To experimentally evaluate the leakage slipper/plate under static conditions, test rig 1 was used, since slipper position could be established accurately using the position transducers. For the case of no tilt, comparisons between experimental and analytical results, given by 
equation (17), for a set of inlet pressures and clearances, are to be found in Figure 5 where it is noticed that a good agreement between measurement and theory is obtained.

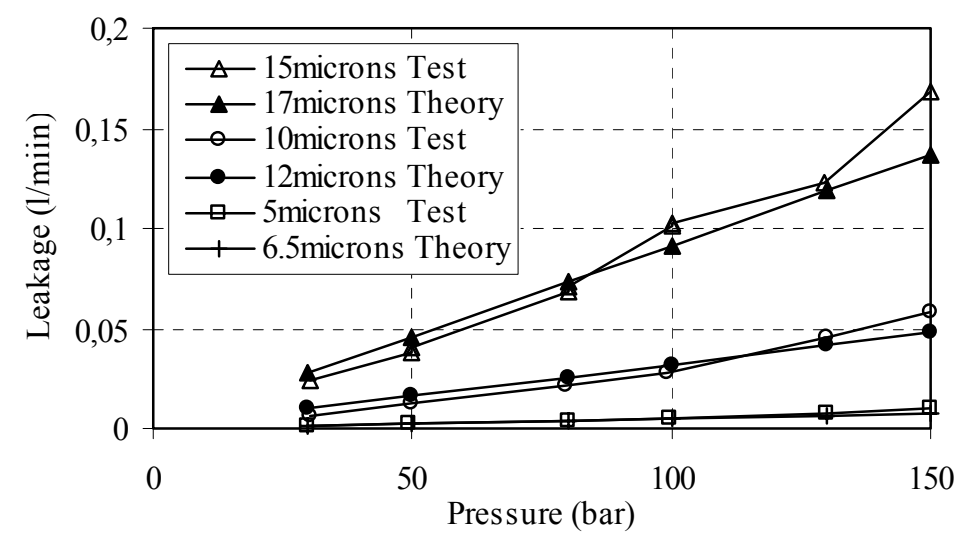

Figure 5. Comparison between theoretical and measured flow rates, test rig 1

It is important to point out that there will be an error in the apparent clearance and the true clearance which varies from point to point due to disk and slipper surface roughness. Surface roughness measurements are shown in Figure 6 where it will be seen that the variation in surface finish is typically 1 micron for both materials.
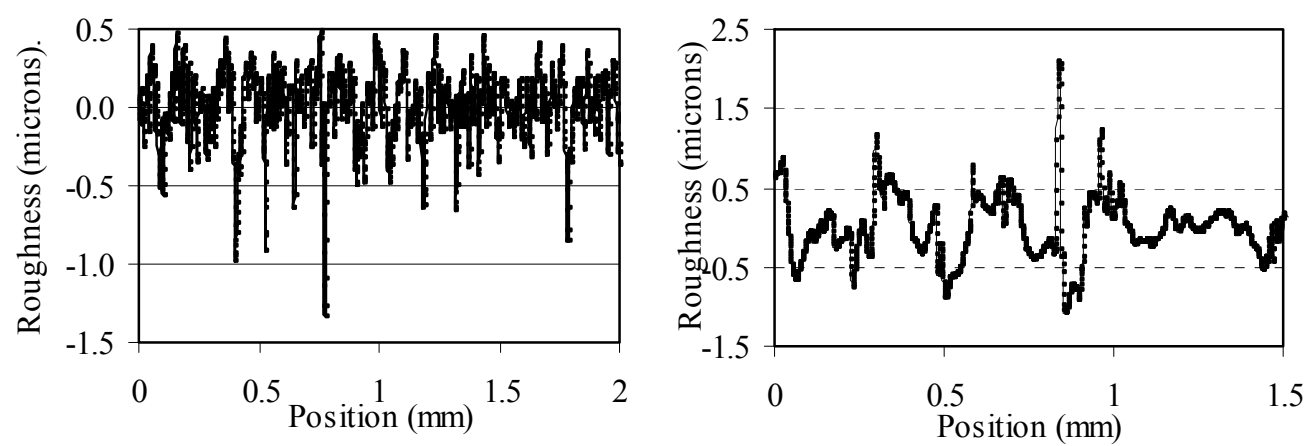

Figure 6. Surface Roughness of the aluminium base and the stainless steel slipper, and in the radial direction, test rig 1

Test rig 1 also allows measurement of the pressure inside the groove at four points. As the slipper had no tilt and no relative movement was considered, the pressure at all four 
measurement points of the groove was the same. Figure 7a shows the analytical radial pressure distribution below the groove for three different inlet pressures using equations (18) and (19). It is noticed that according to the theory the pressure distribution does not depend on the clearance yet the experimental results show that there is a dependency, as demonstrated in Figure $7 b$.

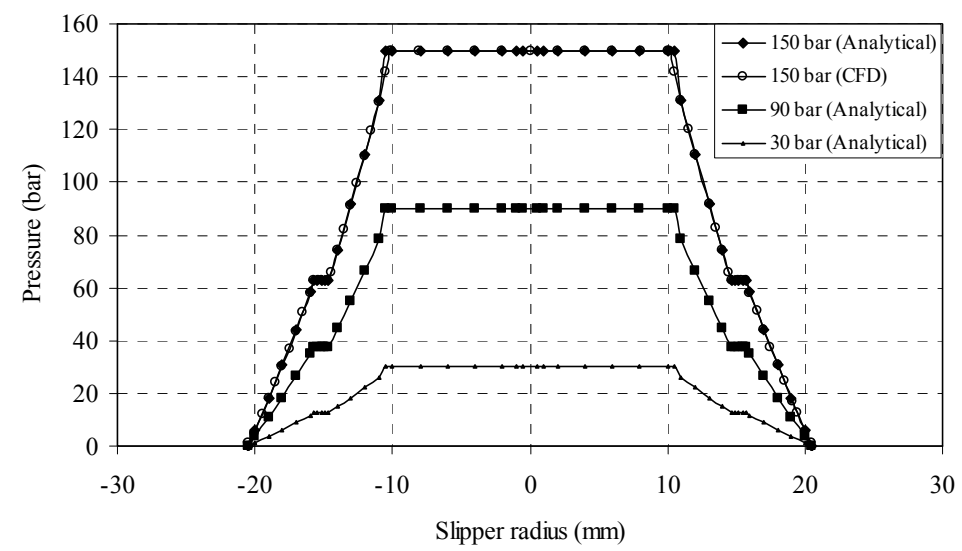

a) Theoretical and CFD radial distribution on pressure.

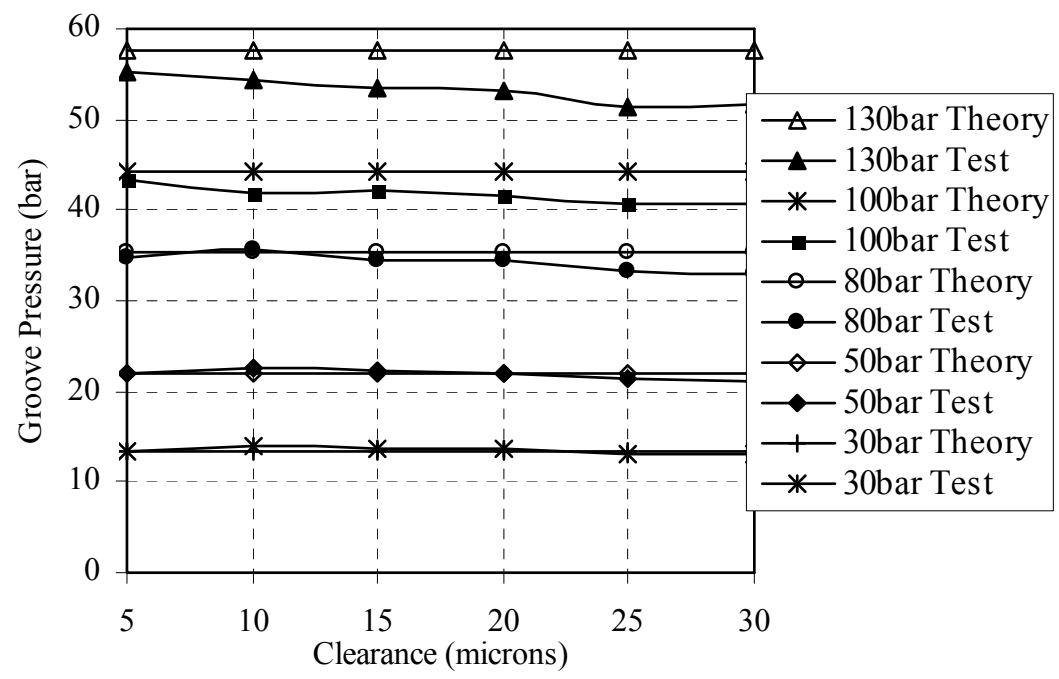

b) Groove pressure variation

Figure 7. Pressure distribution and average groove pressure, test rig 1. (scale 2:1). 
In Figure $7 \mathrm{a}$, the comparison between analytical and CFD results at 150 bar is presented, showing an excellent agreement, and therefore indicating that the theory presented give the same information as a CFD model. On the other hand, the pressure inside the groove was found experimentally to be changing with inlet pressure and central clearance, as can be seen in Figure $7 b$. The average pressure tends to decrease as central clearance increases, indicating that as central clearance increases, the force over the slipper will decrease. The comparisons between analytical and experimental results, Figure $7 b$, show some discrepancies at high pressures and high clearances, which can be understood when it is noticed that the equations proposed consider the shear stresses between the fluid and the slipper/plate boundaries for the ideal case; this is, when the slipper and plate surfaces are perfectly smooth. As demonstrated in Figure 6, in reality these surfaces have a measurable roughness. Therefore the shear stresses occurring between the metal surface and the fluid in the clearance between the slipper and plate will be higher than the theoretical ones. The consequence is that the pressure drop at each slipper land will be higher than the theoretical values presented, and this leads to a lower average pressure inside the groove than the one expected in theory. Shear stresses increase with the velocity gradient, which is higher for higher flow, and this is why the experimental/theoretical discrepancy is higher at higher clearances and pressures. It is important to point out that the clearance slipper swash plate is usually around $5-10$ microns, where the agreement between experimentation and theory is much higher.

Using test rig 2 the pressure was measured at the centre of each slipper land, in two points inside the slipper pocked and inside the groove for a set of different inlet pressures and clearances of 15, 25, 35 microns. Figure 8 compares the average of all the measurements at each inlet pressure with the analytical results, given by the equations (18) and (19). The 
agreement is very good although it is noticed that at high pressures there is some disagreement, the explanation of which was given when Figure $7 \mathrm{~b}$ was discussed.

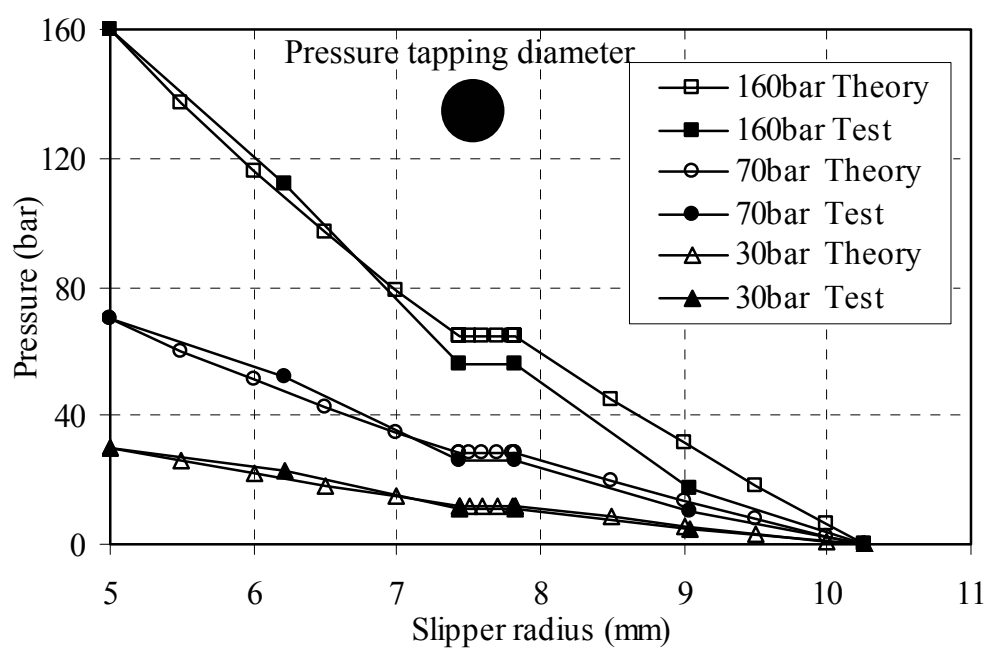

Figure 8. Measured pressure distributions for a set of clearances, test rig 2 (scale 1:1).

These comparisons raise further issues regarding the measurement of pressure for practical piston/slipper assemblies. The pressure tappings were created by drilling ostensibly $0.3 \mathrm{~mm}$ diameter holes, and the pressure drop over this distance is $12 \mathrm{bar}$ for an inlet pressure of 160bar. The exact location of the pressure tappings with respect to the slipper cannot be precisely measured for test units of this scale. In addition any variation in the set clearance or the induction of tilt, during testing cannot also be determined. The net result is that it is proposed for this test rig that the experimental error for pressure measurement is \pm 6 bar at the highest inlet pressure used of 160 bar. Figure 8 shows that the comparison between theory and measurement is good for the inner land but with experimental measurements lower than predicted for the outer land, particularly at the highest pressure. A displacement error of $0.3 \mathrm{~mm}$ for the pressure tapping position in this region would explain the difference. 


\subsubsection{The effect of groove position on force and leakage.}

When designing a slipper, it should be realised that a priory, the smaller the slipper the larger the pump mechanical efficiency, then higher dimension means higher weigh and therefore higher amount of energy is needed to move the piston/slipper assembly, nevertheless, as defined in [30-33] the frictional power loss linked with the slipper dimensions, must be considered when aiming to fully analyse slipper efficiency. Also the slipper should create enough lift to compensate for the force acting at the opposite end of the piston while maintaining a small oil film between the slipper and the swash plate. It then needs to be recalled that the thicker the oil film the lower the pump volumetric efficiency. In order to increase slipper stability while running around the swash plate, some manufacturers have decided to use grooves. Notice that when the slipper slides around the swash plate, during about 150 degrees the pressure on the top of the piston is high, and according to $[17,18]$ the slipper runs nearly flat, but when the piston faces the tank kidney port, the slipper tilt increases sharply. Then at each revolution, the slipper needs to accommodate from a very high tilt condition to a nearly flat position, good slipper stability it is required under such conditions. Slipper stability it is also required when running nearly flat around the swash plate, since metal to metal contact should be avoided. In some cases the grooves are vented with the intention of reducing slipper spin, and this will allow hydrodynamic lift but not hydrostatic lift. However, the use of non vented grooves allows the entire slipper including the groove to create both hydrostatic and hydrodynamic lift. This means that the slipper external diameter can be smaller, maintaining a higher mechanical efficiency. If just the slipper lift characteristics are to be taken into account, the use of a non grooved slipper with a bigger central pocket would be desirable, yet slipper stability might be compromised. If a bigger central pocket is used, the remaining slipper 
land becomes smaller, wear is more rapid which would create higher leakages and thus a decrease in volumetric efficiency. This is why a compromise has to be reached between achieving a lift via increasing the central pocket diameter and compromising slipper stability, or achieving the same lift using a smaller central pocket diameter and inserting a non vented groove. This aspect of the analysis presented is considered to be very relevant to pump manufacturers.

A further advantage of the equations proposed is that slipper performance can now be evaluated for different groove positions. Equations (17) and (21) are used to calculate the leakage flow rate and slipper lift, given the pressures at the slipper central radius $r_{1}$ and external radius $r_{5}$. Some results for lift and flow rate are shown in Figure 9 for variations in groove inner $r_{3}$ and outer radius $r_{4}$ and considering $r_{2} \leq r_{3} \leq r_{4}$.

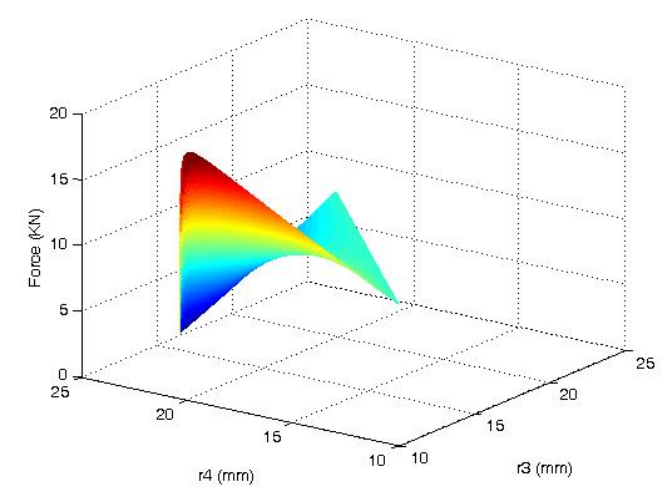

a)

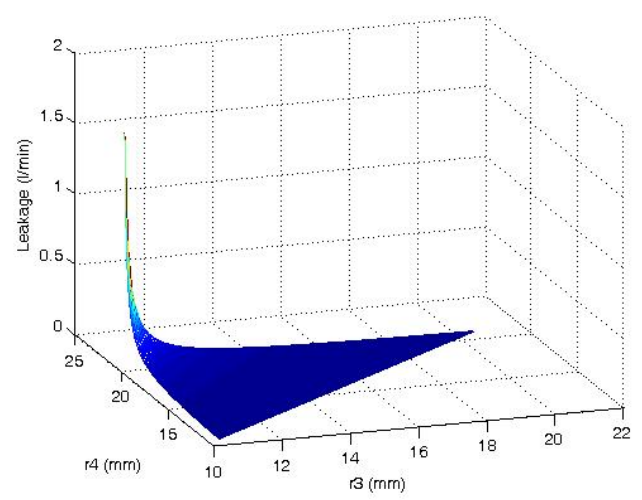

b)

Figure 9. Force and leakage over the original single groove slipper (scale 2:1) when modifying groove dimensions $r_{3}$ and $r_{4}$. Groove depth is maintained constant at $0.8 \mathrm{~mm} . \mathrm{h}_{2}$ $=\mathrm{h}_{4}=10$ microns. Inlet pressure 150 bar, applicable to test rig 1. a) Force; b) Leakage.

These figures demonstrate that groove length and position for given slipper dimensions will drastically change the slipper performance. This could not have been deduced from previous work and illustrates a particular design feature of the analytical approach presented. Figures $9 a$, $b$, demonstrate that for a specific radius $r_{3}$, the modification of $r_{4}$ in 
the range selected will create an increase or decrease in lift while the leakage flow rate will always suffer an increase, the minimum leakage will always occur for a non grooved slipper. For the specific boundary conditions set, there is a unique relationship between $r_{3}$ and $r_{4}$ that will give maximum lift. Notice that according to the force diagram, Figure 9a, the best groove to create maximum lift would be the one covering the entire slipper land and almost reaching the slipper external diameter, in other words, the best groove to achieve maximum lift, is the one which extends the slipper pocked to nearly the external slipper diameter. However, an increase in force via using such a groove would bring a huge increase of leakage.

In order to further clarify the effect of a groove on a non tilted slipper, Figure 10 presents the force and leakage variation as a percentage of the flat slipper without a groove, for a set of groove position central radii while maintaining constant groove dimensions. It clearly demonstrates that the inclusion of a groove may increase or decrease the force compared with a non grooved slipper, but the leakage will always increase. Such percentage variation is independent of the slipper/plate clearance and the inlet pressure. A comparison between the leakage obtained using the theory presented and the CFD model has also been undertaken, showing a very good agreement. 


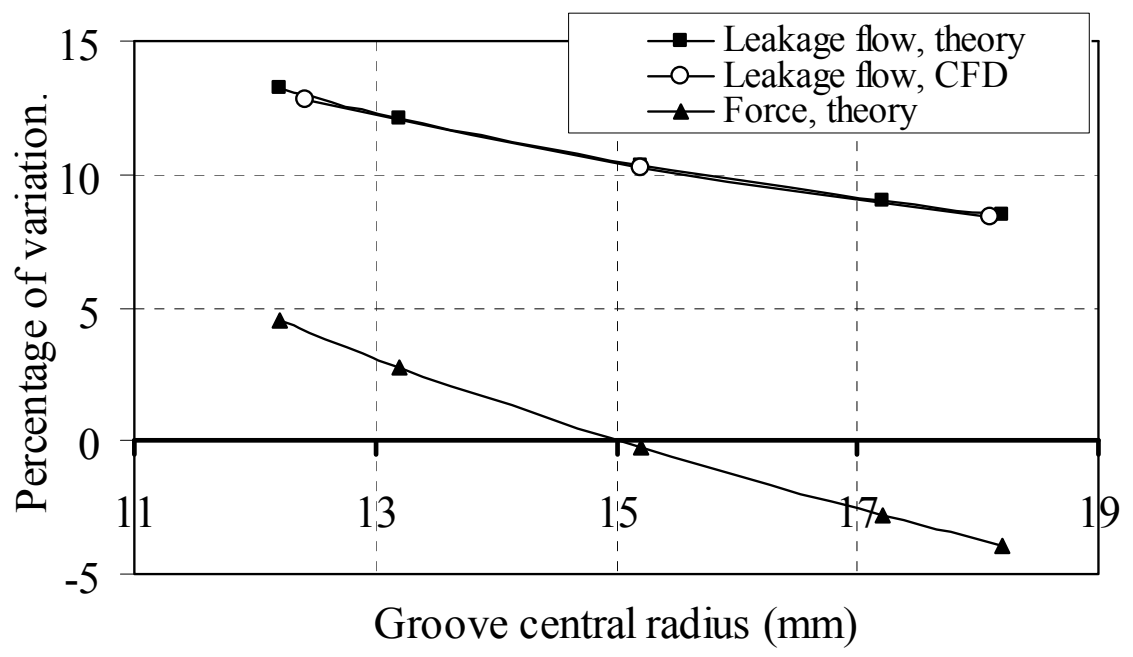

Figure 10. Leakage flow and force variation, as a percentage of the non grooved case.

\subsection{Slipper dynamics.}

The groove size remains constant.

\subsubsection{The effect of pump turning speed on leakage and groove pressure, no tilt.}

It is generally assumed that a groove will maintain a constant pressure along its length tending to give stability to the unit, and this idea may well stem from the use of grooves on pistons or slippers that may experience tilt. Since the equations presented do not consider the effect of tangential velocity, such effects have been studied experimentally using test rig 1. When studying slipper dynamics, two main considerations need to be kept in mind, disk axial displacement and disk runout. During experimental work it was noticed that although the clearance between slipper and plate is set statically, such clearance changes with turning speed, even if the inlet pressure remains constant. The runout has a complex behaviour since for a given pressure and a given turning speed it could be fluctuating. It is necessary to point out that in both cases the fluctuations may be just a few microns, yet such fluctuations are very relevant when attempting to validate the leakage flow rate. Using a specific data acquisition system written in Labview, and utilising the three position transducers described in Figure 3, it is possible to measure dynamically the disk runout at 
each point. Figure 11 shows an example of how the average distance changes with pressure and turning speed, where it is seen that as the plate starts to move the average clearance suddenly increases. It then tends to decrease as the plate turning speed increases, and notice that the biggest displacements occur at smaller pressures. Axial piston test rigs of the type used in this study, although manufactured to a high static tolerance, cannot operate without runout. This does mean that in practice a correction factor for measured flow rate must be included for theoretical validation. Figure 12 shows disk runout over one revolution and its variation with pressure and turning speed. Equation (17) shows that the leakage flow rate changes as a function of the (clearance) $)^{3}$ and therefore if an approximation is made that the dynamic plate runout can be approximated as a sine wave, the real mean dynamic clearance can be estimated using equation (23).

$$
h=h_{o} \sqrt[3]{1+\frac{3}{2}\left(\frac{\alpha}{h_{o}}\right)^{2}}
$$

Equation (23) is derived in the appendix, $\mathrm{h}_{0}$ is the mean dynamic distance slipper plate, and $\alpha$ is the runout amplitude.

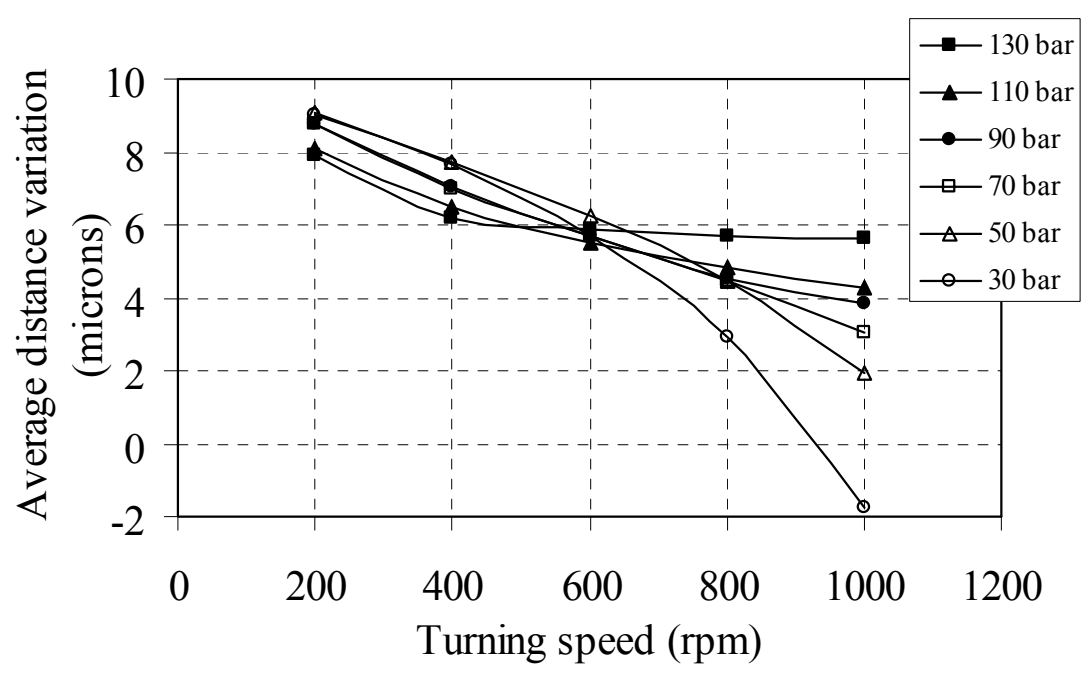

Figure 11. Average slipper/plate distance variation with pressure and turning speed.

(10 microns, flat slipper) 

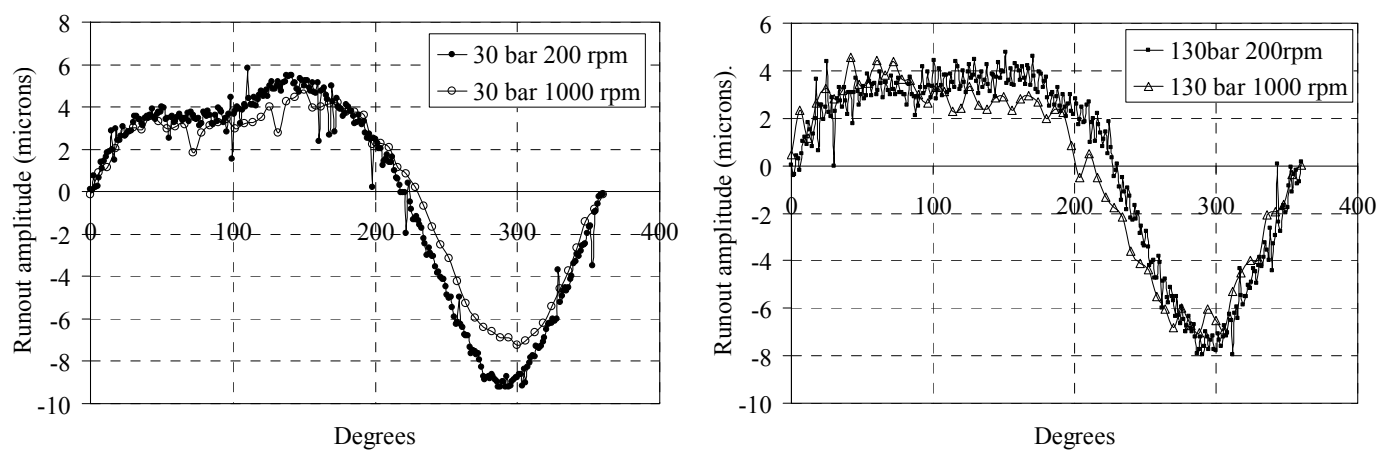

Figure 12. Runout amplitude at two different pressures and turning speeds. (10 microns, flat slipper).

Comparisons between measurement and theory, with its mean clearance corrected for dynamic fluctuation, are shown in Figure 13 and indicate a good agreement. the static leakage flow equation produces the same results as the experimental ones when turning speed is considered, Therefore it is shown that for slippers running parallel to the plate, the effect of turning speed on the leakage flow rate is very small. The same conclusion was reached via the 3D-CFD simulation presented in this paper and also via a different computational model presented in Kumar et al [28].

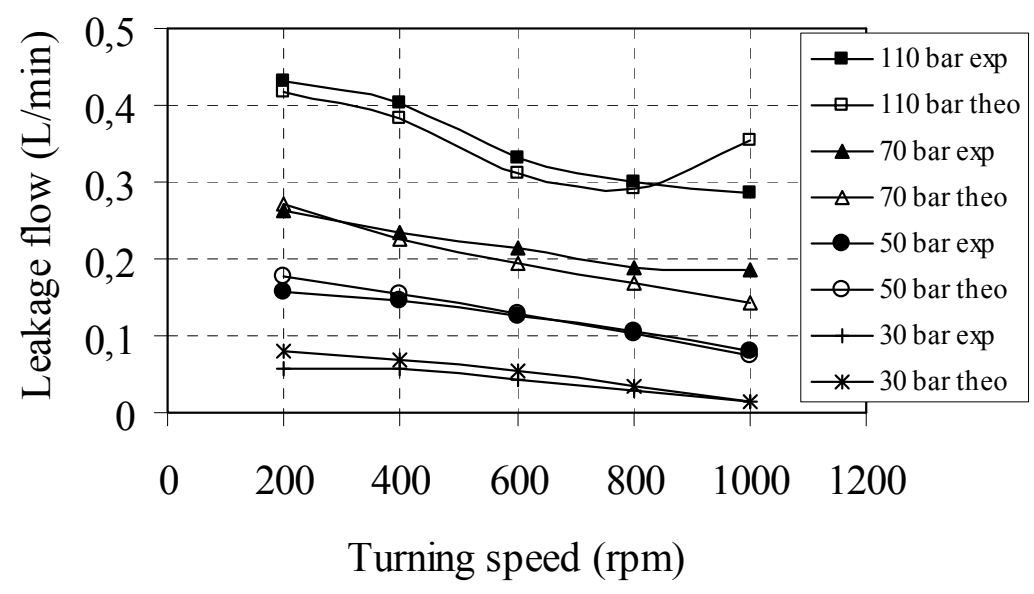

a) 15 microns initial slipper/plate static clearance. 


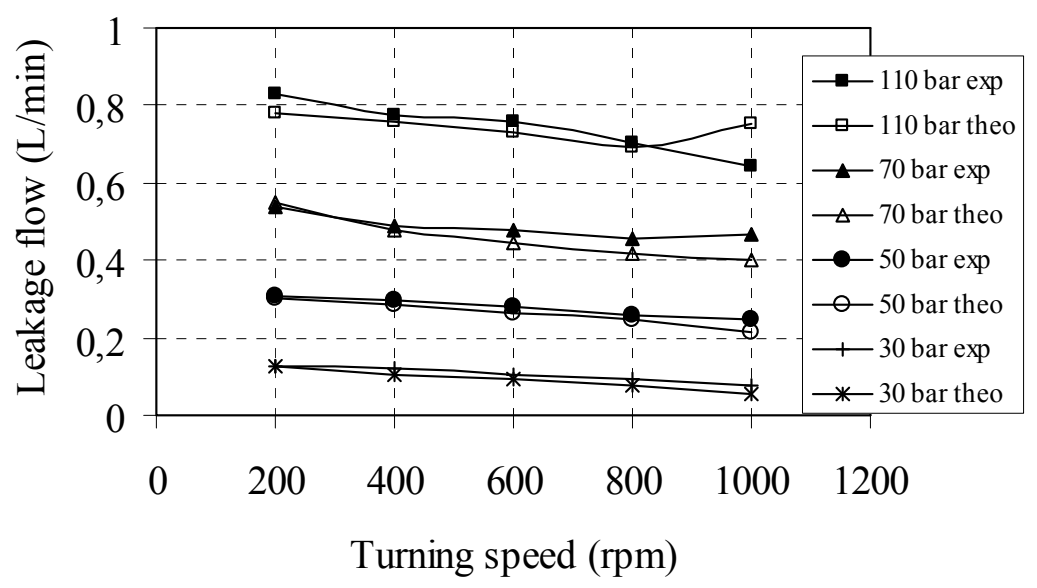

b) 20 microns initial slipper/plate static clearance.

Figure 13. Leakage flow slipper/plate as a function of inlet pressure and turning speed. Comparison between the experimental and the static theoretical results.

It is also noticed in Figure 13 that at high turning speeds and pressures, the theoretical and the experimental results show some differences. An increase of the oil temperature of less than two degrees would explain these differences. The main conclusion from this section is that for the non-tilted condition, the leakage flow rate remains independent of plate turning speed and just dependent on clearance and inlet pressure.

\subsubsection{Effect on tilt and turning speed on slipper performance.}

Slippers are designed to run almost parallel to the swash plate. This means that lift is created mostly hydrostatically, hydrodynamic lift being just an small percentage (around $5 \%$ ) of the total lift. Nevertheless in this section the effect of tangential velocity on tilted slippers with a groove will be discussed. Leakage and average pressure distribution inside the groove would be presented as a function of tilt and tangential velocity. The main parameters related with tilt are defined in Figure 2 and Table 2. Figure 14 presents the average pressure inside the slipper groove for a set of inlet pressures and turning speeds, 
again the film thickness has been assessed by taking into account the weighed average of the disk runout and the disk mean axial displacement.

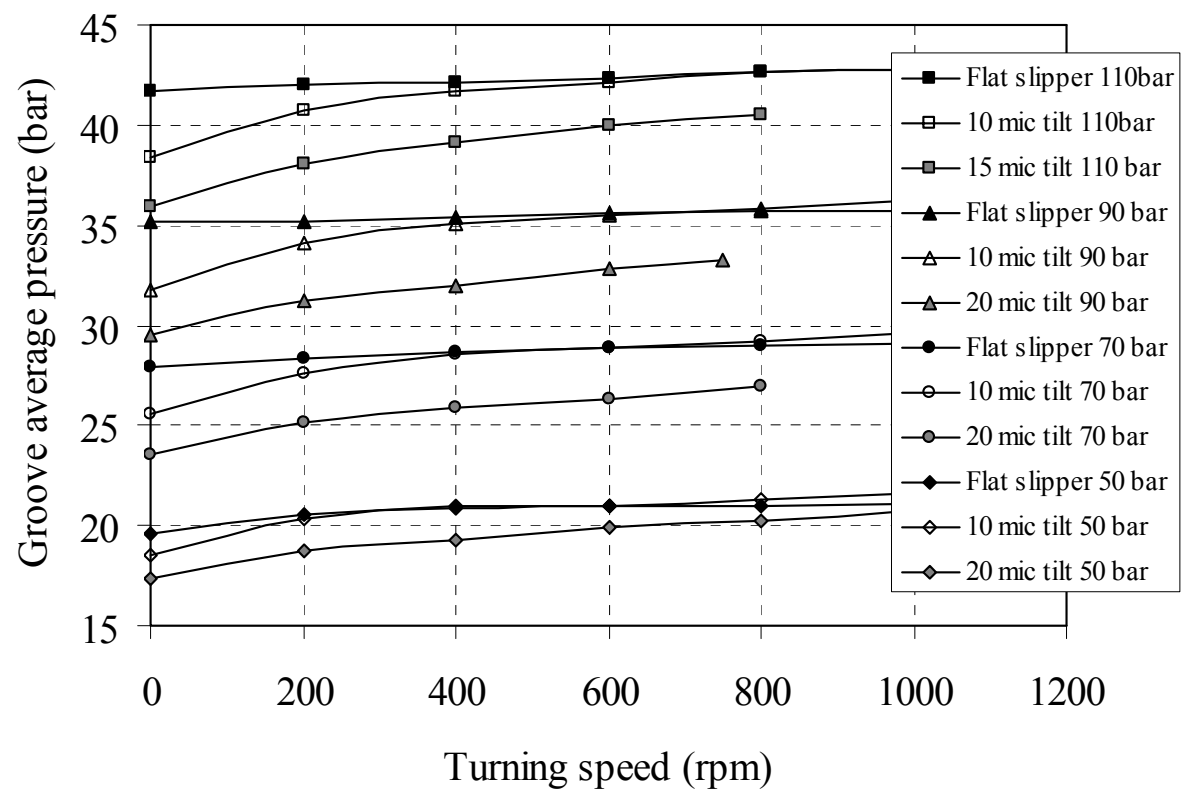

Figure 14. Average pressure inside the groove for several inlet pressures and initial static slipper/plate clearances and tilts.

The results show that for the non-tilted slipper case, the pressure at the four cardinal points of the groove remains the same and this pressure slightly increases with turning speed, demonstrating that the lift force will remain constant with turning speed. Also during experimental work it was found that as the clearance increases, the average groove pressure slightly decreases. Such an effect is well explained when considering that an increase of the film thickness creates an increase of flow and the pressure decay along the slipper first land depends directly on the shear stresses on the slipper face, which increase with the flow. Figure 14 also presents the effect on the groove average pressure, with slipper tilt, where it is demonstrated that as tilt increases the average pressure inside the groove decreases. The average pressure will quickly increase with the increase of turning speed, demonstrating 
that for slippers with tilt the increase of turning speed will bring an increase of lift. It is also interesting to realize that the results presented in Figure 14 are very much dependent of the clearance, except for the non-tilted slipper case.

It is very important to point out that the effect of tangential velocity increases the pressure difference inside the groove between the leading and the trailing edge of the slipper. This increase in pressure difference, although small, will be higher for higher clearances, as Figure 15 presents, demonstrating that at high clearances, the actual groove depth is not enough to maintain a constant pressure along its path.

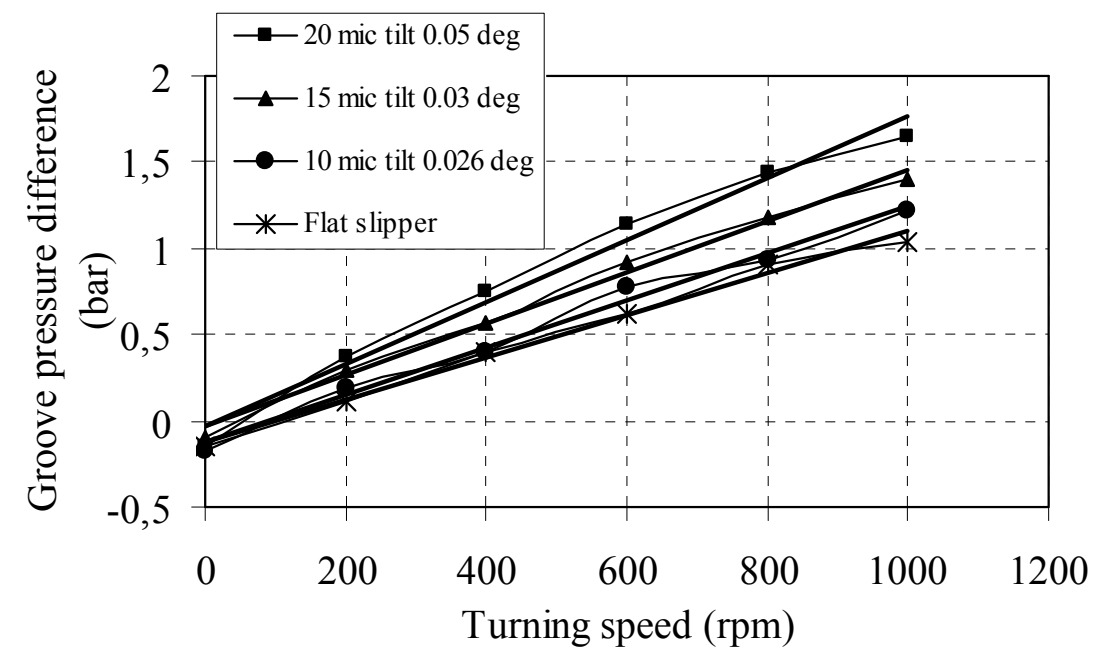

Figure 15. Pressure difference between the trailing and the leading edge of the slipper groove, as a function of slipper tilt and turning speed.

Figure 16 presents the leakage variation with rotational speed for a central initial static clearance of 15 microns and with a tilt of 0.03 degrees. 


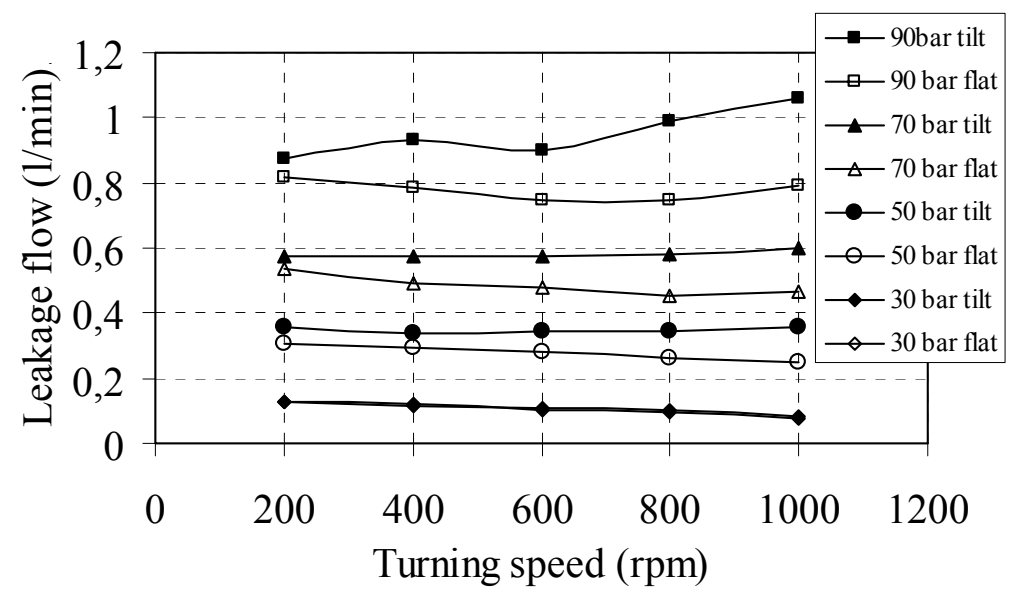

Figure 16. Comparison between flat and tilt slipper performance with turning speed. Initial static central clearance 15 microns, 0,03 degrees tilt.

The results are compared with the ones obtained for the non-tilted slipper at the same initial static clearance. It clearly shows that the leakage obtained with a tilted slipper is always higher than the one obtained for the non-tilted case. Since it has been earlier demonstrated that the leakage for the non-tilted slipper remains constant with turning speed, Figure 16 demonstrates that the effect of turning speed on a tilt slipper, tends to increase the leakage flow rate. Such an increase appears to be more relevant at higher pressures. This effect has been experimentally observed in all the tests performed, yet, it was noticed that at small clearances, the heat generated by the test rig was being transferred to the fluid thereby decreasing the viscosity and therefore increasing the overall leakage flow. At high clearances nevertheless, the flow passing through the test rig, was big enough to dissipate the heat without suffering a relevant temperature increase. This is why the graph presented in Figure 16 is for an initial static central clearance of 15 microns, its equivalent average dynamic central clearance, once axial displacement and plate runout was considered, being 21 microns. 


\section{Conclusions}

1.-A new set of equations and tests are presented capable of directly evaluating leakage flow rate, the hydrostatic pressure distribution and lift on a grooved slipper having an ostensibly constant clearance. In practice, experimental measurements must consider:

- surface roughness

- pressure tapping point diameter and its relative position between slipper and base

- test rig small displacement under pressure.

The hydrostatic theoretical characteristics of a grooved slipper have been validated experimentally.

2.-It is demonstrated that the equations can be used to optimise the slipper design and clarifies the effect on the slipper force and leakage when groove position and dimensions are modified.

3.-Lift is higher when the groove is located along the inner land and decreases as the groove move towards the external radius. However, leakage increases as the groove moves towards the slipper pocket. The inclusion of a groove in a slipper will result in an increase of leakage flow rate.

4.-For a slipper held parallel to the plate, is has been demonstrated via CFD analysis and experimentally that the leakage flow rate will remain constant and therefore independent of turning speed. For the case of tilted slippers, the experiments have demonstrated that the increase of plate turning speed will bring a small increase in leakage flow rate. 
5.-For both a non-tilted and tilted slipper, the pressure difference between the trailing and leading edge of the slipper will increase with turning speed. For the tilted slipper case, the average pressure inside the groove sharply increases with turning speed and such an increase is almost negligible for the flat slipper case. It is therefore to be expected that the lift force onto a tilt slipper will increase as turning speed increases, while it will remain rather constant for the non-tilted slipper case.

6.-A particular feature of the design equations presented is that they can be used to determine the groove geometry for optimum lift at a specified leakage flow rate. A methodology has been established to design grooved systems; therefore a door to use the same methodology for other applications is opened.

7.-Test rig or a practical pump runout can be significant when considering the dynamic mean clearance. A method has been proposed for estimating the change in mean clearance if the runout can be approximated by a sinusoid, and does produce a better comparison between measurement and theory.

\section{Acknowledgements.}

The authors wish to thank Robert Jones, a Technician at Cardiff University School of Engineering, who machined and built the variable-speed test rig to such a high standard.

JM Bergada wants to thank the Spanish "Ministerio de Ciencia e Innovacion" for the grant PR2008-0105 received in 2008, which has helped in making this research possible. 


\section{References.}

[1] Hooke CJ and Kakoullis YP (1981) "The effects of centrifugal load and ball friction on the lubrication of slippers in axial piston pumps". $6^{\text {th }}$ International Fluid Power Symposium, 179-191, Cambridge, England.

[2] Kobayashi S, Hirose M, Hatsue J, Ikeya M (1988). "Friction characteristics of a ball joint in the swashplate type axial piston motor". Proc Eighth International Symposium on Fluid Power, Birmingham, England, J2- pp565-592.

[3] Fisher MJ (1962). "A theoretical determination of some characteristics of a tilted hydrostatic slipper bearing”. BHRA Report RR 728 April 1962.

[4] Böinghoff O (1977) „Untersuchen zum Reibungsverhalten der Gleitschuhe in Schrägscheiben-Axialkolbenmascinen“. VDI-Forschungsheft 584. VDI-Verlag. pp1-46.

[5] Hooke CJ and Kakoullis YP (1978). "The lubrication of slippers on axial piston pumps". $5^{\text {th }}$ International Fluid Power Symposium September 1978, B2- pp13-26. Durham, England.

[6] Iboshi N and Yamaguchi A (1982). "Characteristics of a slipper Bearing for swash plate type axial piston pumps and motors, theoretical analysis". Bulletin of the JSME, Vol 25, No 210, pp 1921-1930.

[7] Iboshi N and Yamaguchi A (1983). "Characteristics of a slipper Bearing for swash plate type axial piston pumps and motors, experimental". Bulletin of the JSME, Vol 26, No 219, pp 1583-1589.

[8] Hooke CJ and Kakoullis YP (1983). "The effects of non flatness on the performance of slippers in axial piston pumps". Proceedings of the Institution of Mechanical Engineers. Vol. 197 C, pp 239-247. 
[9] Hooke CJ and Li KY (1988). "The lubrication of overclamped slippers in axial piston pumps centrally loaded behaviour". Proceedings of the Institution of Mechanical Engineers. Vol 202, No C4, pp 287-293.

[10] Hooke CJ and Li KY (1989). "The lubrication of slippers in axial piston pumps and motors. The effect of tilting couples". Proceedings of the Institution of Mechanical Engineers Vol 203, part C, pp 343-350.

[11] Takahashi K and Ishizawa S (1989). "Viscous flow between parallel disks with time varying gap width and central fluid source". JHPS International Symposium on Fluid Power, Tokyo, March 1989, pp 407-414.

[12] Koc E and Hooke CJ (1996). "Investigation into the effects of orifice size, offset and overclamp ratio on the lubrication of slipper bearings". Tribology International, Vol. 29, No 4, pp 299-305.

[13] Koc E and Hooke CJ (1997). "Considerations in the design of partially hydrostatic slipper bearings". Tribology International, Vol 30, No. 11, pp 815-823.

[14] Tsuta T, Iwamoto T, Umeda T (1999). “Combined dynamic response analysis of a piston-slipper system and lubricants in hydraulic piston pump". Emerging Technologies in Fluids, Structures and Fluid/Structure Interactions. ASME Vol 396 pp 187-194.

[15] Li KY and Hooke CJ (1991). "A note on the lubrication of composite slippers in water based axial piston pumps and motors". Wear, 147, pp 431-437.

[16] Koc E, Hooke CJ, Li KY (1992) “Slipper balance in axial piston pumps and motors". Trans ASME, Journal of Tribology, Vol 114, pp 766-772.

[17] Harris RM, Edge KA, Tilley DG (1996). "Predicting the behaviour of slipper pads in swashplate-type axial piston pumps". ASME Journal of Dynamic Systems, Measurement and control. Vol 118, pp 41-47. 
[18] Wieczoreck U and Ivantysynova M (2000) “CASPAR-A computer aided design tool for axial piston machines". Proceedings of the Power Transmission Motion and Control International Workshop, PTMC2000, Bath, UK. pp 113-126.

[19] Crabtree AB, Manring ND (2005) “Johnson RE. Pressure measurements for translating hydrostatic trust bearings". International Journal of Fluid Power. Vol. 6 N 3.

[20] Kazama T (2005). "Numerical simulation of a slipper model for water hydraulic pumps/motors in mixed lubrication". Proceedings of the $6^{\text {th }}$ JFPS International Symposium on Fluid Power, TSUKUBA 2005. November 7-10.

[21] Kakoulis YP (1977)."Slipper lubrication in axial piston pumps”. M.Sc. Thesis University of Birmingham.

[22] Johnson RE. and Manring ND. "Translating circular trust bearings". Journal of fluid Mechanics. (2005) Vol 530, pp 197-212.

[23] Bergada JM and Watton J (2002). "A direct leakage flow rate calculation method for axial pump grooved pistons and slippers, and its evaluation for a 5/95 fluid application". $5^{\text {th }}$ JFPS international Symposium on fluid power, Nara Japan. November 13.

[24] Bergada JM and Watton J (2002). “Axial piston pump slipper balance with multiple lands". ASME International Mechanical Engineering Congress and exposition. IMECE 2002. New Orleans Louisiana November 17-22 Vol 2 paper 39338.

[25] Bergada JM and Watton J. (2005). Force and flow through hydrostatic slippers with grooves. The $8^{\text {th }}$ International symposium on fluid control measurement and visualization. Chengdu, China 2005. Paper number 240.

[26] Watton J. (2007). Modelling, Monitoring and Diagnostic Techniques for Fluid Power Systems. Published by Springer. 
[27] Watton J. (2009). Fundamentals of fluid Power control. Published by Cambridge University Press.

[28] Bergada JM; Haynes JM; Watton J. (2008) "Leakage and groove pressure of an axial piston pump slipper with multiple lands.” Tribology transactions. Vol 51 N 4 pp 469-482.

[29] Kumar S; Bergada JM; Watton J. (2009) “Axial Piston Pump Grooved Slipper analysis by CFD simulation of three dimensional NVS equation in Cylindrical coordinates." Computers and Fluids, Vol 38 N 3 pp 648-663.

[30] Huanlong L; Jian K; Guozhi W; Lanying Y. (2006) "Research on the lubrication characteristics of water hydraulic slipper friction pairs". Proceedings IMechE, Journal of Mechanical Engineering Science. Vol 220 part C pp 1559-1567.

[31] Canbulut F; Sinanoglu C; Yildirim S; Koç E. (2004) "Design of neural network model for analysing hydrostatic circular recessed bearings with axial piston pump slipper". Industrial lubrication and Tribology. Vol 56 No 5 pp 288-299.

[32] Canbulut F; Koç E; Sinanoglu C. (2009) "Design of artificial neural networks for slipper analysis of axial piston pumps".Industrial lubrication and Tribology. Vol 61 No 2 pp 67-77.

[33] Canbulut F; Sinanoglu C; Koç E. (2009) "Experimental analysis of frictional power loss of hydrostatic slipper bearings“.Industrial lubrication and Tribology. Vol 61 No 3 pp 123-131.

[34] Cameron A. (1966). The principles of lubrication. Published by Longman . 


\section{Appendix 1.}

The pressure distribution at each slipper land for the present case $n=4$ is given by the following equations:

$$
\mathrm{p}_{1}=\mathrm{p}_{\text {inlet }}-\frac{\left(\mathrm{p}_{\text {inlet }}-\mathrm{p}_{\text {outlet }}\right)}{\frac{1}{\mathrm{~h}_{1}^{3}} \ln \left(\frac{\mathrm{r}_{2}}{\mathrm{r}_{1}}\right)+\frac{1}{\mathrm{~h}_{2}^{3}} \ln \left(\frac{\mathrm{r}_{3}}{\mathrm{r}_{2}}\right)+\frac{1}{\mathrm{~h}_{3}^{3}} \ln \left(\frac{\mathrm{r}_{4}}{\mathrm{r}_{3}}\right)+\frac{1}{\mathrm{~h}_{4}^{3}} \ln \left(\frac{\mathrm{r}_{5}}{\mathrm{r}_{4}}\right)} \frac{1}{\mathrm{~h}_{1}^{3}} \ln \left(\frac{\mathrm{r}}{\mathrm{r}_{1}}\right)
$$

Range of applicability $\mathrm{r}_{1}<\mathrm{r}<\mathrm{r}_{2}$

$$
\mathrm{p}_{2}=\mathrm{p}_{\text {inlet }}-\frac{\left(\mathrm{p}_{\text {inlet }}-\mathrm{p}_{\text {outlet }}\right)}{\frac{1}{\mathrm{~h}_{1}^{3}} \ln \left(\frac{\mathrm{r}_{2}}{\mathrm{r}_{1}}\right)+\frac{1}{\mathrm{~h}_{2}^{3}} \ln \left(\frac{\mathrm{r}_{3}}{\mathrm{r}_{2}}\right)+\frac{1}{\mathrm{~h}_{3}^{3}} \ln \left(\frac{\mathrm{r}_{4}}{\mathrm{r}_{3}}\right)+\frac{1}{\mathrm{~h}_{4}^{3}} \ln \left(\frac{\mathrm{r}_{5}}{\mathrm{r}_{4}}\right)}\left[\frac{1}{\mathrm{~h}_{1}^{3}} \ln \left(\frac{\mathrm{r}_{2}}{\mathrm{r}_{1}}\right)+\frac{1}{\mathrm{~h}_{2}^{3}} \ln \left(\frac{\mathrm{r}}{\mathrm{r}_{2}}\right)\right]
$$

Range of applicability $\mathrm{r}_{2}<\mathrm{r}<\mathrm{r}_{3}$

$$
\mathrm{p}_{3}=\mathrm{p}_{\text {inlet }}-\frac{\left(\mathrm{p}_{\text {inlet }}-\mathrm{p}_{\text {outlet }}\right)}{\frac{1}{\mathrm{~h}_{1}^{3}} \ln \left(\frac{\mathrm{r}_{2}}{\mathrm{r}_{1}}\right)+\frac{1}{\mathrm{~h}_{2}^{3}} \ln \left(\frac{\mathrm{r}_{3}}{\mathrm{r}_{2}}\right)+\frac{1}{\mathrm{~h}_{3}^{3}} \ln \left(\frac{\mathrm{r}_{4}}{\mathrm{r}_{3}}\right)+\frac{1}{\mathrm{~h}_{4}^{3}} \ln \left(\frac{\mathrm{r}_{5}}{\mathrm{r}_{4}}\right)}\left[\frac{1}{\mathrm{~h}_{1}^{3}} \ln \left(\frac{\mathrm{r}_{2}}{\mathrm{r}_{1}}\right)+\frac{1}{\mathrm{~h}_{2}^{3}} \ln \left(\frac{\mathrm{r}_{3}}{\mathrm{r}_{2}}\right)+\frac{1}{\mathrm{~h}_{3}^{3}} \ln \left(\frac{\mathrm{r}}{\mathrm{r}_{3}}\right)\right]
$$

Range of applicability $\mathrm{r}_{3}<\mathrm{r}<\mathrm{r}_{4}$

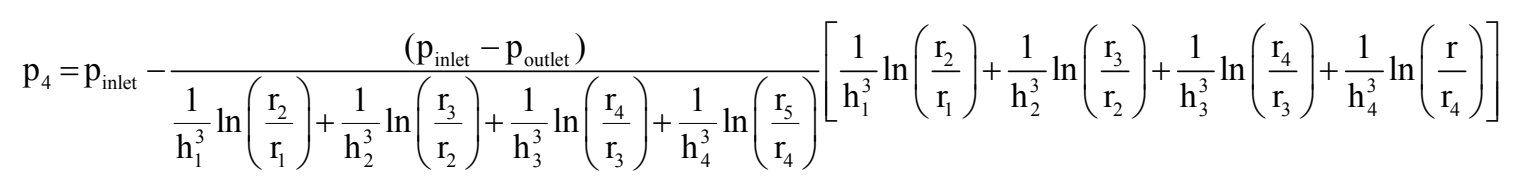

Range of applicability $\mathrm{r}_{4}<\mathrm{r}<\mathrm{r}_{5}$

The leakage flow equation for the actual slipper $n=4$, will take the form:

$$
\mathrm{Q}=\frac{\pi}{6 \mu} \frac{\left(\mathrm{p}_{\text {inlet }}-\mathrm{p}_{\text {outlet }}\right)}{\frac{1}{\mathrm{~h}_{1}^{3}} \ln \left(\frac{\mathrm{r}_{2}}{\mathrm{r}_{1}}\right)+\frac{1}{\mathrm{~h}_{2}^{3}} \ln \left(\frac{\mathrm{r}_{3}}{\mathrm{r}_{2}}\right)+\frac{1}{\mathrm{~h}_{3}^{3}} \ln \left(\frac{\mathrm{r}_{4}}{\mathrm{r}_{3}}\right)+\frac{1}{\mathrm{~h}_{4}^{3}} \ln \left(\frac{\mathrm{r}_{5}}{\mathrm{r}_{4}}\right)}
$$

The equation giving the lift force on the slipper face as a function of the slipper dimensions and the inlet pressure, for the actual slipper under study, number of lands $n=4$ is: 


$$
\begin{aligned}
\mathrm{F}_{\text {lift }}= & \mathrm{P}_{\text {inlet }} \pi\left(\mathrm{r}_{5}^{2}-\mathrm{r}_{1}^{2}\right)-\mathrm{C} \pi \mathrm{r}_{5}^{2}\left(\frac{1}{\mathrm{~h}_{1}^{3}} \ln \left(\frac{\mathrm{r}_{2}}{\mathrm{r}_{1}}\right)+\frac{1}{\mathrm{~h}_{2}^{3}} \ln \left(\frac{\mathrm{r}_{3}}{\mathrm{r}_{2}}\right)+\frac{1}{\mathrm{~h}_{3}^{3}} \ln \left(\frac{\mathrm{r}_{4}}{\mathrm{r}_{3}}\right)+\frac{1}{\mathrm{~h}_{4}^{3}} \ln \left(\frac{\mathrm{r}_{5}}{\mathrm{r}_{4}}\right)\right) \\
& +\mathrm{C} \pi\left(\frac{1}{\mathrm{~h}_{1}^{3}} \frac{\mathrm{r}_{2}^{2}-\mathrm{r}_{1}^{2}}{2}+\frac{1}{\mathrm{~h}_{2}^{3}} \frac{\mathrm{r}_{3}^{2}-\mathrm{r}_{2}^{2}}{2}+\frac{1}{\mathrm{~h}_{3}^{3}} \frac{\mathrm{r}_{4}^{2}-\mathrm{r}_{3}^{2}}{2}+\frac{1}{\mathrm{~h}_{4}^{3}} \frac{\mathrm{r}_{5}^{2}-\mathrm{r}_{4}^{2}}{2}\right)
\end{aligned}
$$

where the constant $\mathrm{C}$ takes the form.

$$
\mathrm{C}=\frac{\mathrm{p}_{\text {inlet }}-\mathrm{p}_{\text {outlet }}}{\frac{1}{\mathrm{~h}_{1}^{3}} \ln \left(\frac{\mathrm{r}_{2}}{\mathrm{r}_{1}}\right)+\frac{1}{\mathrm{~h}_{2}^{3}} \ln \left(\frac{\mathrm{r}_{3}}{\mathrm{r}_{2}}\right)+\frac{1}{\mathrm{~h}_{3}^{3}} \ln \left(\frac{\mathrm{r}_{4}}{\mathrm{r}_{3}}\right)+\frac{1}{\mathrm{~h}_{4}^{3}} \ln \left(\frac{\mathrm{r}_{5}}{\mathrm{r}_{4}}\right)}
$$

\section{Appendix 2.}

To calculate the average dynamic clearance due to runout, the following procedure has been established assuming that the flow is proportional to $\mathrm{h}^{3}$ :

$$
\mathrm{Q}_{\mathrm{o}}=\mathrm{k} \mathrm{h}_{\mathrm{o}}{ }^{3}
$$

With run-out then average the flow over one cycle can be given as:

$$
\mathrm{Q}=\frac{\mathrm{k}}{2 \pi} \int_{0}^{2 \pi}\left(\mathrm{h}_{\mathrm{o}}+\alpha \sin \theta\right)^{3} \mathrm{~d} \theta=\mathrm{k}\left[\mathrm{h}_{\mathrm{o}}^{3}+\frac{3 \alpha^{2} \mathrm{~h}_{\mathrm{o}}}{2}\right]
$$

This gives :

$$
\mathrm{Q}=\mathrm{Q}_{\mathrm{o}}\left[1+\frac{3}{2}\left(\frac{\alpha}{\mathrm{h}_{\mathrm{o}}}\right)^{2}\right]
$$

Hence a modified dynamic mean clearance equivalent to:

$$
h=h_{o} \sqrt[3]{1+\frac{3}{2}\left(\frac{\alpha}{h_{o}}\right)^{2}}
$$

